\title{
Coastal Stratocumulus Dissipation Dependence on Initial Conditions and Boundary Forcings in a Mixed-Layer Model
}

\author{
MÓNICA ZAMORA ZAPATA \\ Department of Mechanical and Aerospace Engineering, University of California, San Diego, La Jolla, California \\ JOEL R. NORRIS \\ Scripps Institution of Oceanography, University of California, San Diego, La Jolla, California \\ JAN KLEISSL \\ Department of Mechanical and Aerospace Engineering, University of California, San Diego, La Jolla, California
}

(Manuscript received 17 September 2019, in final form 23 May 2020)

\begin{abstract}
The impact of initial states and meteorological variables on stratocumulus cloud dissipation time over coastal land is investigated using a mixed-layer model. A large set of realistic initial conditions and forcing parameters are derived from radiosonde observations and numerical weather prediction model outputs, including total water mixing ratio and liquid water potential temperature profiles (within the boundary layer, across the capping inversion, and at $3 \mathrm{~km}$ ), inversion-base height and cloud thickness, large-scale divergence, wind speed, Bowen ratio, sea surface fluxes, sky effective radiative temperature, shortwave irradiance above the cloud, and sea level pressure. We study the sensitivity of predicted dissipation time using two analyses. In the first, we simulate 195 cloudy days (all variables covary as observed in nature). We caution that simulated predictions correlate only weakly to observations of dissipation time, but the simulation approach is robust and facilitates covariability testing. In the second, a single variable is varied around an idealized reference case. While both analyses agree in that initial conditions influence dissipation time more than forcing parameters, some results with covariability differ greatly from the more traditional sensitivity analysis and with previous studies: opposing trends are observed for boundary layer total water mixing ratio and Bowen ratio, and covariability diminishes the sensitivity to cloud thickness and inversion height by a factor of 5 . With covariability, the most important features extending predicted cloud lifetime are (i) initially thicker clouds, higher inversion height, and stronger temperature inversion jumps, and (ii) boundary forcings of lower sky effective radiative temperature.
\end{abstract}

\section{Introduction}

Marine stratocumulus ( $\mathrm{Sc}$ ) clouds cover a large area of the planet at the eastern side of oceans where upwelling keeps the sea colder and at latitudes where the subsiding branch of the Hadley cell pushes the atmospheric boundary layer (ABL) down and caps it with warm air, creating an inversion layer that limits the vertical cloud extent. The main physical processes controlling the evolution of Sc clouds are radiation, turbulence, surface fluxes, entrainment, and precipitation (Wood 2012; Stevens 2005; Nieuwstadt and Duynkerke 1996). Sc clouds

\footnotetext{
Corresponding author: Mónica Zamora Zapata, mzamoraz@ eng.ucsd.edu
}

are maintained by convective turbulent motions, driven mainly by cloud-top radiative cooling that generates sinking plumes and cools the ABL (Lilly 1968). The turbulent motions allow water vapor from the surface to mix and rise up to the condensation level to form a cloud. Near the top of the cloud, there is a complex interface zone exposed to entrainment of air from the free troposphere (Mellado 2017).

Marine Sc clouds have a net cooling effect on the planet (Hartmann et al. 1992) and their impact under climate change conditions is still a matter of research (Zelinka et al. 2017; Bony and Dufresne 2005; Duynkerke and Teixeira 2001). Coastal cities near Sc regions are affected by their presence-not only in terms of climate, but also from the perspective of solar energy generation. 
As solar heating overcomes cloud-top radiative cooling, clouds over land thin during the day, warming the ABL, and changing its turbulent structure (Fang et al. 2014). No solar radiation is present during the night, resulting in more effective radiative cooling, which causes cloud growth. During the day, solar electricity generation ramps up as Sc clouds dissipate in the morning hours (Jamaly et al. 2013; Wellby and Engerer 2016) or an extended shortfall of solar generation occurs when Sc clouds persist for the whole day. A better understanding of Sc cloud dissipation can help improve solar energy forecasting in these regions.

Different physical processes and meteorological parameters affect the inland coverage of marine Sc clouds and the dissipation time over coastal land. For marine clouds, some parameters have been linked to decreased cloudiness: greater sea surface temperatures (SST) (Hanson 1991; Seethala et al. 2015), weaker lowertropospheric stability (LTS) (Klein and Hartmann 1993; Wood and Bretherton 2006; Klein et al. 1995), weaker horizontal cold-air advection, weaker surface wind speed, a moister free-troposphere, and lower sea level pressure (SLP) (Klein et al. 1995; Seethala et al. 2015). Research has been less extensive over coastal land, where earlier dissipation has been linked to smaller Bowen ratio ( $\mathrm{Bo}$; the ratio between sensible and latent heat fluxes over land) and weaker sea-breeze advection using simple sensitivity analyses (Ghonima et al. 2016; Akyurek and Kleissl 2017).

Most factors do not contribute independently to cloud dissipation because they are interrelated with other variables and covary in nature. Some variables covary due to the nature of physical processes, such as greater SST yielding larger surface heat fluxes. Other variables covary because their definitions are linked, such as lower SST occurring with stronger LTS. Some variables with opposing trends on cloud dissipation can be correlated themselves, causing the total cloud response to be dominated by only one variable and masking the independent effect of the nondominant variable. This is the case for stronger subsidence, which tends to thin Sc clouds, being correlated with larger LTS, which tends to sustain a thicker cloud-their combined occurrence is linked to larger cloudiness due to dominance by LTS (Myers and Norris 2013; Seethala et al. 2015). Such covariability can arise from seasonal trends, such as decreasing LTS cooccurring with increasing SST, which causes cloudiness to decrease from May/June to August/September in Southern California (Clemesha et al. 2016; Klein and Hartmann 1993).

The research to date on coastal Sc dissipation presents several gaps: (i) Only a few parameters have been considered, specifically two in Ghonima et al. (2016), while nine variables have been studied for marine Sc in Seethala et al. (2015). (ii) The parameters do not resemble realistic conditions. Specifically, Ghonima et al. (2016) parameter values for Bowen ratio and sea-breeze advection were chosen ad hoc and only for two idealized cases. (iii) As a result of (ii), covariability effects have been ignored.

In this work, we conduct a comprehensive analysis of how coastal Sc cloud dissipation time depends on initial conditions and boundary forcings, with consideration of covariability. We use a large set of 15 variables measured or derived from realistic meteorological conditions for Southern California as input to a two-column mixed-layer model (MLM) to predict dissipation time (section 2a). The two columns represent ocean and land conditions and allow the modeling of sea-breeze advection over coastal land. Realistic conditions for the MLM are obtained from radiosonde profiles, ground measurements, and NWP models for the 2014-17 summer seasons in Southern California (section 2b). In section 3a, we review the correlations of the variables in the dataset. We perform two analyses in order to consider the impact of covariability on the predicted dissipation time (section $3 b$ ). In the first, coastal Sc evolution is simulated for 195 cloudy days in which the initial conditions and forcing parameters covary as in nature. In the second, simulations are performed in which a single forcing parameter is varied around an idealized, composite reference simulation. Because the different parameters covary in nature, the sensitivity to changes in a single parameter will differ between the two approaches: changes in one variable are accompanied by changes in other variables sampled from their climatological covariation. In this paper, "covariability" refers to the effects of these secondary correlations on changes in the evolution of the cloud and, in particular, on the time of its breakup. In section 3c, we quantify and compare the dissipation time trends obtained by the different approaches. Section 4 contains the conclusions. For an easier reading, a nomenclature is included in appendix A.

\section{Methods}

\section{a. Mixed-layer model framework}

The MLM used in this study follows the implementation of Ghonima et al. (2016) (refer to appendix B for further details). In the MLM, the state of the wellmixed ABL is described by three prognostic equations and several parameterizations. The prognostic equations determine the evolution of the thermodynamic state of the ABL, described by the ABL thickness or inversion-base height $z_{i}$, the mean liquid water potential temperature in the $\mathrm{ABL} \theta_{l}^{\mathrm{BL}}$, and the mean total water 


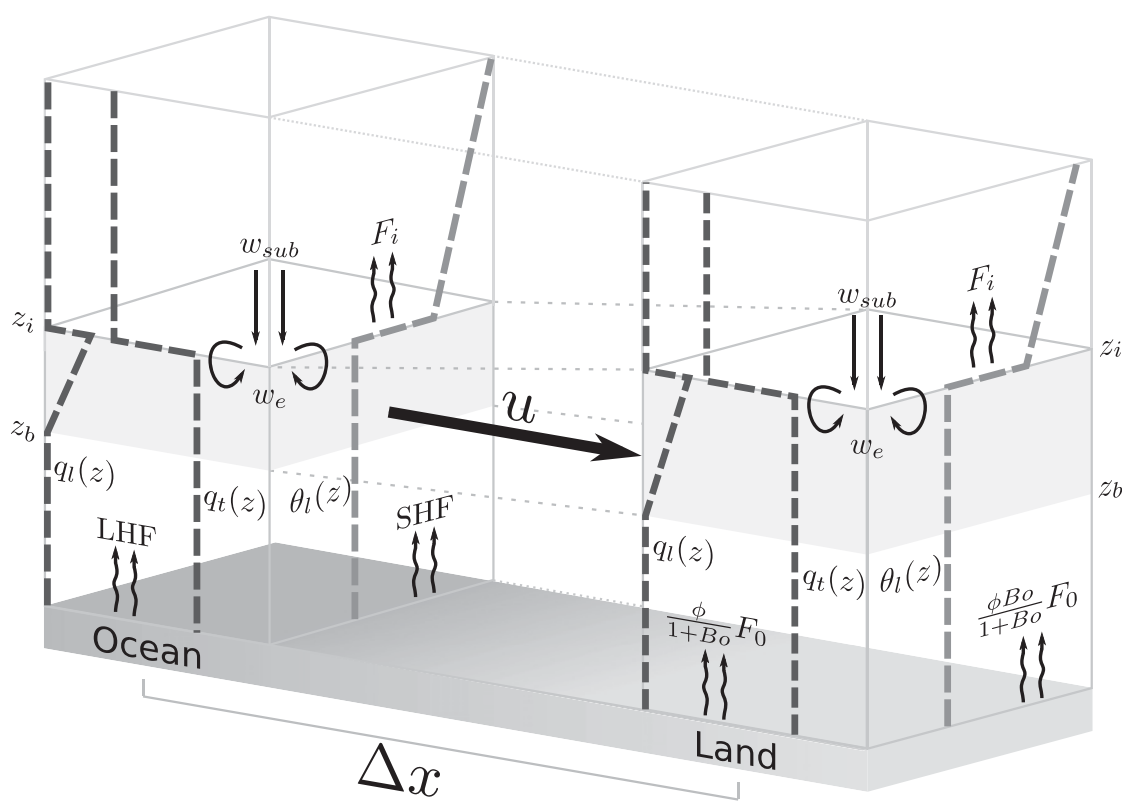

FIG. 1. Two columns are simulated to account for sea-breeze advection. Ocean and land column states are described by their height $z_{i}$, moisture $q_{t}(z)$, and temperature $\theta_{l}(z)$, from which the liquid water profile $q_{l}(z)$ and cloud-base height $z_{b}$ can be derived. Ocean and land have different surface flux conditions, with the ocean having prescribed fluxes of LHF and SHF, while over land the net surface radiative flux $F_{0}$ is partitioned using a Bowen ratio Bo. At the cloud top, both columns are affected by the net radiative flux $F_{i}$ and entrainment fluxes that depend on the inversion jumps. Entrainment mixes air into the columns at a

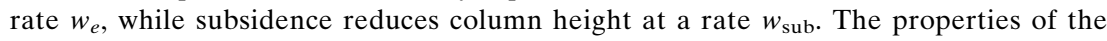
ocean column are advected onto the land column with a wind speed $u$ and considering a distance $\Delta x$ [see Eq. (B5)].

content in the ABL $q_{t}^{\mathrm{BL}}$. Cloud thickness $h$ depends on these three variables, where the cloud-top height is also $z_{i}$ and the cloud-base height depends on $\theta_{l}^{\mathrm{BL}}$ and $q_{t}^{\mathrm{BL}}$. The growth of $z_{i}$ depends on the balance between the entrainment of upper air and large-scale subsidence. Changes in $\theta_{l}^{\mathrm{BL}}$ depend on the balance of radiation and turbulent fluxes, while the evolution of $q_{t}^{\mathrm{BL}}$ is only determined by turbulent fluxes (precipitation is not considered). Consequently, changes in $h$ are affected by all these factors. Aside from the governing equations, parameterizations in the MLM allow quantifying radiation, entrainment of upper air, large-scale subsidence, and turbulent fluxes at the surface and top of the ABL.

Since we are interested in cloud dissipation over coastal land, a Eulerian framework is preferred, which introduces advection tendencies in the prognostic equations. To account for this effect, we model the evolution of two columns: one over the ocean and the other over land, as illustrated in Fig. 1. The dominant wind direction in this region is from the ocean to the land, during day and night, as a consequence of the North Pacific subtropical high and the continental U.S. thermal low during the summer (Halliwell and Allen 1987). Therefore, advection is considered only for the land column, and the advection terms depend on both ocean and land conditions (appendix B).

For this study, we are specifically interested in the effect of different variables on cloud dissipation. We accordingly select relevant meteorological variables used by the equations and parameterizations in the MLM. The variables determine the initial conditions and boundary forcings during the simulation. Initial condition variables include the inversion-base height $z_{i}$, as well as the ABL values of liquid water potential temperature $\theta_{l}^{\mathrm{BL}}$ and total water mixing ratio $q_{t}^{\mathrm{BL}}$, that determine the initial cloud thickness $h$. Thermodynamic values above the $\mathrm{ABL}$ are also part of the initial input, including values at $3 \mathrm{~km}\left(\theta_{l}^{3 \mathrm{~km}}\right.$ and $\left.q_{t}^{3 \mathrm{~km}}\right)$ and inversion jumps $\left(\Delta_{i} \theta_{l}\right.$ and $\left.\Delta_{i} q_{t}\right)$, which are assumed to occur over an infinitesimally thin layer (Lilly 1968).

The parameters used to determine forcings include large-scale, radiative, and turbulent processes. The large-scale parameters are the ABL large-scale divergence $D$ that determines the subsidence rate at the top of the ABL $w_{\text {sub }}$ [Eq. (B2)], an average wind speed $\bar{u}$ for the advection tendencies (appendix B), and SLP. The radiation parameterization has shortwave and longwave components (section $\mathrm{d}$ of appendix B), where the solar 
irradiance above the cloud $\mathrm{SW}_{i}$ along with the cloud properties will determine the shortwave net radiation flux. For the longwave component, the sky effective radiative temperature $T_{\text {sky }}$ represents the longwave radiation gain from the sky above the ABL. Last, turbulent fluxes exist both at the surface and the top of the ABL (section e of appendix B). Surface fluxes depend on the type of column: for the ocean, we prescribe sensible and latent heat fluxes (SHF and LHF) as daily averages, and for the land, we prescribe a Bowen ratio Bo that partitions the sensible and latent heat fluxes. At the top of the ABL, the turbulent fluxes are determined by the inversion jumps $\Delta_{i} \theta_{l}$ and $\Delta_{i} q_{t}$ along with the entrainment rate $w_{e}$. Last, entrainment mixes air from the free troposphere into the ABL through turbulence, which results from a complex combination of radiative cooling, evaporative cooling, and wind shear, among other processes (Mellado 2017). In the MLM, the entrainment parameterization depends on most of the other variables described (section $\mathrm{c}$ of appendix B). Entrainment acts as a regulating mechanism in response to cloud thickness as it promotes thinning for thicker clouds (Zhu et al. 2005). Entrainment also favors dissipation over land as larger surface fluxes increase $w_{e}$ and both surface fluxes and entrainment promote $A B L$ heating, thinning the cloud.

A comment on the choice of the data/modeling tool for the analysis is in order. We use a MLM because it allows a comprehensive sensitivity analysis in an idealized geometry. Conversely, real observations would introduce unknowns, uncertainties, and errors. For example, real 3D topography affects dissipation time due to differential heating and differences in boundary layer height, while the MLM allows removing these effects. Another example is that boundary layer heights are only observed twice per day in reality while the MLM provides a detailed evolution. A detailed discussion of the benefits of the MLM framework is provided in appendix D.

\section{b. Data}

To study how different variables influence Sc dissipation time, we created a comprehensive dataset with realistic Sc conditions for the years 2014-17 in Southern California. It is important to consider realistic conditions to understand if the influence of a variable is actually observable/relevant, as well as to understand which variables need to be measured/obtained to improve cloud dissipation predictions. The dataset contains the variables needed in the MLM: inversion height $z_{i}$, liquid water potential temperature $\theta_{l}(z)$ and total water mixing ratio $q_{t}(z)$ profiles, ABL large-scale divergence $D$, average wind speed $\bar{u}$, Bowen ratio Bo, incoming solar irradiance above the cloud $\mathrm{SW}_{i}$, sky effective radiative temperature $T_{\text {sky }}, \mathrm{SLP}$, and ocean SHF and LHF. The months of May-September are selected as they constitute the Sc cloud season, and also when the highest solar irradiance is available. The variables are obtained from different sources including radiosondes, numerical weather prediction (NWP) model outputs, observations, and radiative models. Further details are provided in appendix $\mathrm{C}$.

ABL thickness $z_{i}$ and profiles of liquid water potential temperature $\theta_{l}(z)$ and total water mixing ratio $q_{t}(z)$ are processed from radiosonde data to be compatible with the MLM framework (section b of appendix C). We analyze early morning radiosondes at the NKX Miramar Marine Corps Air Station in San Diego, California. First, the inversion-base height $z_{i}$ is detected as the starting point of the largest temperature inversion. Next, we check if the state of the ABL could be decoupled using the criterion $\left|\theta_{v b}-\theta_{v 0}\right|>1 \mathrm{~K}$ (Ghate et al. 2015), where $\theta_{v b}$ and $\theta_{v 0}$ are the virtual potential temperature at the radiosonde cloud base [the point where the relative humidity ( $\mathrm{RH}$ ) exceeds $95 \%$ ] and at the surface, respectively. Decoupled cases are discarded because the MLM cannot describe the ABL physics appropriately. For the remaining cloudy cases, the state of the ABL is averaged to create a well-mixed profile described by $\theta_{l}^{\mathrm{BL}}$ and $q_{t}^{\mathrm{BL}}$. Last, the free troposphere is included by considering data above the inversion region up to $3 \mathrm{~km}$. While moisture above the inversion is assumed to be constant and represented by an average value of total water mixing ratio $q_{t}^{3 \mathrm{~km}}$ and a sharp inversion jump of total water mixing ratio $\Delta_{i} q_{t}$, the liquid water potential temperature is fitted into a linear profile and represented by the value of the fit at $3 \mathrm{~km} \theta_{l}^{3 \mathrm{~km}}$ and by the sharp inversion jump $\Delta_{i} \theta_{l}$. Figure 2 shows an example of the processed well-mixed ABL structure. Since the initial state is derived from the radiosonde launched at 0300 LST (1100 UTC), we use that time to initialize the simulations. Furthermore, we assume that this early state is representative of both ocean and coastal land and thus, start the MLM with the same initial condition for both columns. This assumption is justified as the region experiences a sea breeze during day and night and nighttime surface radiative cooling over land is small due to the Sc cloud cover.

The radiation model in the MLM depends on $\mathrm{SW}_{i}$ for the shortwave and $T_{\text {sky }}$ for the longwave radiation fluxes. For obtaining $\mathrm{SW}_{i}$, we assume that there are no other cloud layers overhead-typical for the summer season in Southern California (Christensen et al. 2013) - and calculate the daily maximum of global horizontal irradiance (GHI) from a clear-sky model (Ineichen and Perez 2002). For obtaining $T_{\text {sky }}$, we solve for the longwave radiative fluxes 


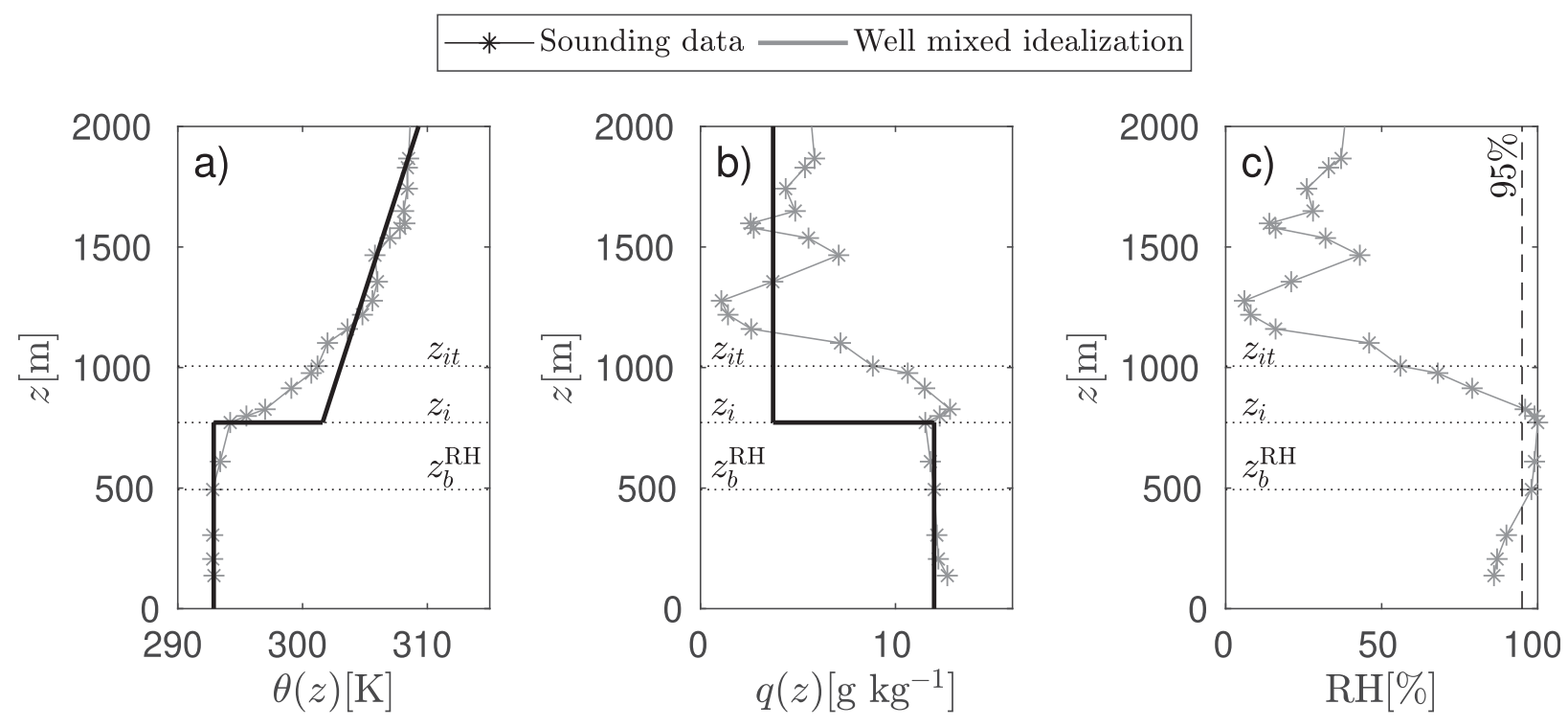

FIG. 2. Mixed-layer idealization for $21 \mathrm{Jul}$ 2014. We detect the inversion region from radiosonde data (gray), and compute a well-mixed profile (black) by averaging properties in the ABL and tropospheric regions. The well-mixed profile is compatible with the MLM.

across the whole atmosphere by inputting the temperature profiles from the radiosonde into the Streamer radiative transfer model (Key and Schweiger 1998) and calculating $T_{\text {sky }}$ as the blackbody temperature from the longwave downwelling flux at the top of the cloud (section c of appendix C).

We estimate $\bar{u}$ and SLP from measurements at the NKX METAR weather station. We compute $\bar{u}$ as the average of the westerly wind speeds between 0500 and 2100 LST and scale a 10 -yr average daily profile to recreate the diurnal cycle (see Fig. C1b). This daily profile never reaches zero, so advection is continually present during the day (section e of appendix $\mathrm{C}$ ). We compute SLP as a daily average.

For the turbulent fluxes at the surface, we take different approaches for the ocean and land columns. For the ocean column, the prescribed values of SHF and LHF are computed with a bulk formula (section e of appendix C) from observations of wind speed $\bar{u}$ and daily averages of SST at the Torrey Pines Outer station obtained from the National Data Buoy Center (NDBC) (NOAA 2017). For the land column, we estimate a daily Bowen ratio Bo at NKX by analyzing in-house operational runs of the Weather Research and Forecasting (WRF) Model. Bo is computed as the ratio between SHF and LHF at the nearest grid point to the NKX station, averaged between 0800 and 1500 LST (section $d$ of appendix C).

Last, we estimate large-scale divergence $D$ from the North American Mesoscale Forecasting System (NAM) as the partial derivative of pressure vertical velocity $\omega$ with respect to pressure in the ABL (section $d$ of appendix C).

\section{c. Steady thickness initialization}

The MLM is initialized at 0300 LST prior to sunrise, when we expect a stable Sc behavior. Nevertheless, we occasionally observed large changes in modeled cloud thickness in the first few hours after initialization but still prior to sunrise, indicating possible inconsistencies in the initial state. For reference, Duynkerke et al. (2004, their Fig. 4) observed $\Delta \mathrm{LWP} / \Delta t$ tendencies of 2.8 and $7.6 \mathrm{~g} \mathrm{~m}^{-2} \mathrm{~h}^{-1}$ at $0300-0400 \mathrm{LST}$. In contrast, the firsthour average of $\Delta \mathrm{LWP} / \Delta t$ for our preliminary MLM runs ranged between -42 and $12 \mathrm{~g} \mathrm{~m}^{-2} \mathrm{~h}^{-1}$.

The reasons for large model tendencies following initialization are multifold: (i) the well-mixed approach fits the radiosonde data to a slightly different state (Fig. 2); (ii) radiosonde measurement errors, especially in the humidity measurement; (iii) LWP is not measured and has to be derived using a crude model $\left[\mathrm{LWP}=\int_{0}^{z_{i}} \rho(z) q_{l}(z) d z\right.$, where $\rho(z)$ is the density of air]; (iv) the MLM does not adequately describe all ABL physics; and (v) uncertainties in the estimated large-scale divergence. Since the variable interdependencies will be studied as a function of the initial conditions, it is important that the initial conditions are representative of the first few hours of the simulations. While initial variables should reflect real conditions as much as possible, our main objective is to understand the sensitivities of Sc evolution. Therefore, a stable, selfconsistent MLM initialization is the priority and slight 

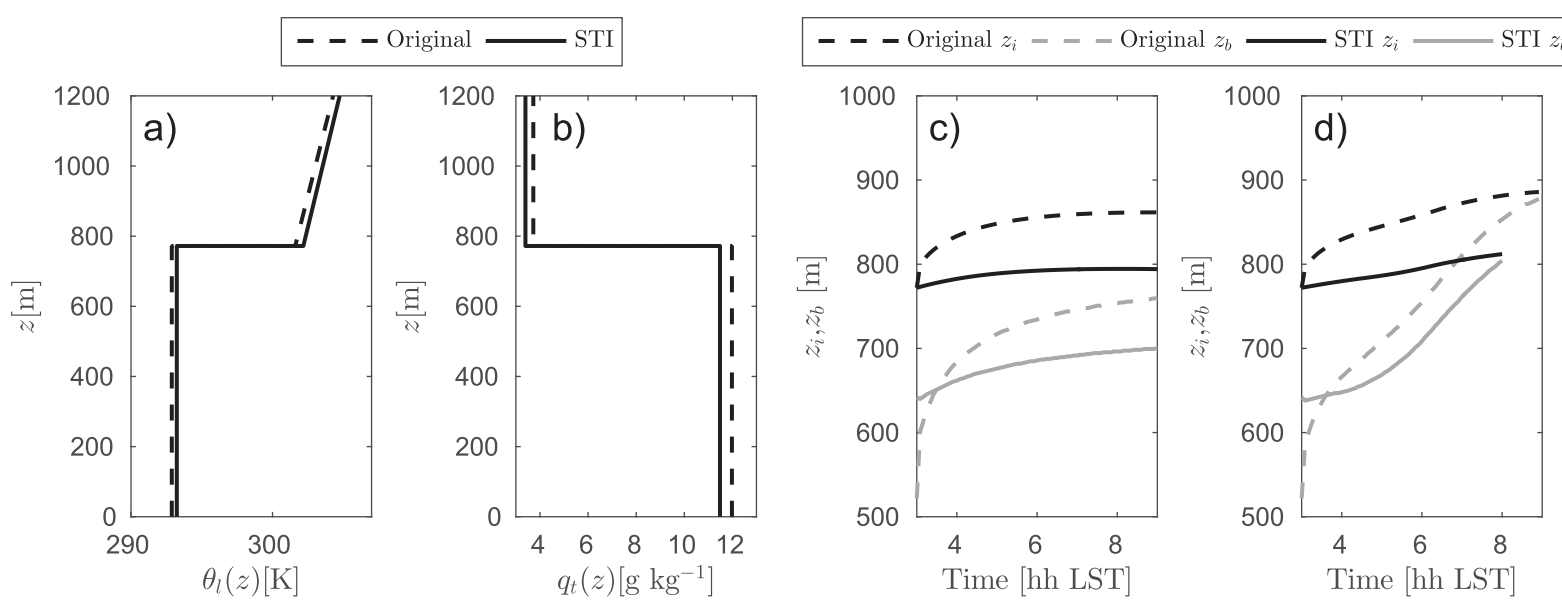

FIG. 3. Effect of the steady thickness initialization (STI) for 21 Jul 2014. The changes to the original sounding (dashed lines) for (a) $\theta_{l}(z)$ and (b) $q_{t}(z)$ are shown in solid lines. MLM simulated cloud boundaries $z_{i}$ and $z_{b}$ for the (c) ocean and (d) land column for the original properties and the modified STI.

deviation from measured conditions when needed is tolerated. The steady thickness initialization (STI) method was developed to create a stable initial condition from the measured profiles.

We seek a more stable state by keeping $z_{i}$ constant and varying the set of thermodynamic variables $\mathbf{s} \equiv\left(\theta_{l}^{\mathrm{BL}}, \Delta_{i} \theta_{l}, q_{t}^{\mathrm{BL}}, \Delta_{i} q_{t}\right)$. For mathematical consistency, the tropospheric mixing ratio $q_{t}^{3 \mathrm{~km}}$ will also be modified (since it is the sum of ABL and inversion jump quantities). We do not seek a state with zero tendency because (i) we want to avoid deviating too much from the original state, (ii) there is no unique value of $\mathbf{s}$ that satisfies the steady thickness condition (van der Dussen et al. 2014, their Fig. 3), and (iii) it has been observed that the $z_{i}$ tendencies at dawn are small but not zero. Instead, we seek for a close, more stable state $\mathbf{s}$ by thresholding the rate of change of thickness:

$$
\left|\frac{\partial h}{\partial t}\right|=\left|\frac{\partial z_{i}}{\partial t}-\frac{\partial z_{b}}{\partial t}\right|<5 \times 10^{-3}\left[\mathrm{~m} \mathrm{~s}^{-1}\right] .
$$

Using an iterative gradient descent method the four variables change at the same time [Eq. (2)], in an amount proportional to the local gradient of the thickness tendency:

$$
\mathbf{s}_{n+1}=\mathbf{s}_{n}-\operatorname{sgn}\left[\frac{\partial h}{\partial t}\left(\mathbf{s}_{n}\right)\right] \xi \nabla \frac{\partial h}{\partial t}\left(\mathbf{s}_{n}\right),
$$

where $\xi$ is the proportionality constant used to follow the gradient; $\xi=0.1$ yielded satisfactory results for most days. We compute the gradient with second-order central finite differences using a step of $0.1 \mathrm{~K}$ or $0.1 \mathrm{~g} \mathrm{~kg}^{-1}$ in each component of $\mathbf{s}$ and iterate until the thinning or thickening is less than $5 \mathrm{~mm} \mathrm{~s}^{-1}$ [Eq. (1)]. An example of the effect of the STI is shown in Fig. 3. The strong thinning experienced in the first hour of simulation with the original initial conditions is greatly reduced, and the STI initial conditions yield $-6.4<\Delta \mathrm{LWP} / \Delta t<12 \mathrm{~g} \mathrm{~m}^{-2} \mathrm{~h}^{-1}$, in better agreement with observations in Duynkerke et al. (2004, their Fig. 4).

Finally, we remove STI states that lie far from the original using a squared distance threshold:

$$
d^{2}=\sum_{i=1}^{4}\left(\frac{s_{i}^{\mathrm{STI}}-s_{i}}{s_{i}}\right)^{2}=0.005,
$$

where $s_{i}$ and $s_{i}^{\mathrm{STI}}$ are the components of $\mathbf{s}$ prior and after the STI method is applied, respectively. Twelve cases are removed in this way. For the final set of 195 cases used in the analysis, 115 cases were not modified by the STI, as the original state was already steadier than $5 \mathrm{~mm} \mathrm{~s}^{-1}$, and for the 80 cases that were modified, the average $d^{2}$ was 0.0007 .

\section{d. Model runs}

The STI-adjusted dataset becomes the new input to the MLM. The initial conditions are the STI thermodynamic profiles derived from the radiosonde. The other variables are related to forcings at the boundaries of the ABL, such as airmass advection and fluxes at the surface and inversion levels. The MLM predicts the evolution of the cloud and yields the cloud dissipation time over land. Simulations are terminated when clouds dissipate because the increase in solar heating of the ABL prevents cloud reformation until evening and because several model 
assumptions (e.g., the entrainment calculation) are no longer valid.

\section{e. Data subsetting}

Some of the original 278 cloudy and not decoupled days produced results inconsistent with the MLM assumptions: (i) STI leading to a cloudless state; (ii) negative entrainment values that may be related to decoupling (section c of appendix B); (iii) clouds whose base reached the surface during the simulation (the longwave radiation scheme in the MLM may not represent fog conditions accurately); (iv) otherwise extremely thick clouds that could precipitate (precipitation is not modeled in the MLM), using a threshold of LWP $=250 \mathrm{~g} \mathrm{~m}^{-2}$; and (v) days with precipitation at the METAR station. After filtering these cases out, we were left with a dataset of 195 days.

\section{f. Sensitivity analyses}

\section{1) All variables Covary on 195 ReAl Days}

We analyze the results of the MLM runs for the diverse conditions of 195 days that span a broad range of the parameter space and display covariability. We investigate the trends in dissipation time over land $t_{\text {diss }}$ in relationship to each one of the variables of interest.

\section{2) SINGLE-VARIABLE CHANGES FROM A REFERENCE CASE}

The results of the cases with covariability can be difficult to analyze, as different impacts can be enhanced or diminished by the combination of different variables. To aid the understanding of the covariability analysis, we first identify the individual influence of each variable on dissipation time through a traditional sensitivity analysis. We vary one variable at a time from an idealized reference case composed of the medians of all the MLM input variables: $z_{i}, q_{t}^{\mathrm{BL}}, \Delta_{i} q_{t}, q_{t}^{3 \mathrm{~km}}, \theta_{l}^{\mathrm{BL}}, \Delta_{i} \theta_{l}, \theta_{l}^{3 \mathrm{~km}}, \bar{u}, \mathrm{SW}_{i}$, $D$, Bo, SLP, $T_{\text {sky }}$, SHF, and LHF. The purpose of using this idealized reference case is to be able to change most variables in their observed ranges. A set of five equidistant points between the percentiles $p_{25}$ and $p_{75}$ of the observed distribution for that input variable is simulated.

The other 14 variables are held constant with the following exceptions: (i) $\Delta_{i} q_{t}$ and the tropospheric mixing ratio are varied together for self-consistency [Eq. (C3)]; (ii) $z_{i}$ is varied following two approaches: (ii-a) variations of $z_{i}$ alone, which yields different cloud thicknesses, and (ii-b) variations of $z_{i}$ with constant cloud thickness obtained by adjusting $q_{t}^{\mathrm{BL}}$; (iii) variations of cloud thickness $h$ with constant $z_{i}$ and $\theta_{l}^{\mathrm{BL}}$ obtained by adjusting $q_{t}^{\mathrm{BL}}$.

The motivation for (ii-b) is to assess the changes of $z_{i}$ without the feedbacks related to the abrupt change in cloud thickness. We refer to (ii-b) as varying $\left.z_{i}\right|_{h}$, and we calculate the adjusted $q_{t}^{\mathrm{BL}}\left(\left.z_{i}\right|_{h}\right)$ using $\partial z_{b} / \partial q_{t}^{\mathrm{BL}}$ [Ghonima et al. 2015, their Eq. (15)] [Eq. (3)]:

$$
\begin{aligned}
\left(q_{t}^{\mathrm{BL}}\right)_{\text {new }} & =\left(q_{t}^{\mathrm{BL}}\right)_{\text {old }}+\Delta z_{i} \frac{\partial q_{t}}{\partial z_{b}} \\
& =\left(q_{t}^{\mathrm{BL}}\right)_{\text {old }}\left[1+\frac{g}{R_{d} T_{b}}\left(1-\frac{L_{\mathrm{lv}} R_{d}}{C_{p} R_{v} T_{b}}\right) \Delta z_{b}\right],
\end{aligned}
$$

where $\left(q_{t}^{\mathrm{BL}}\right)_{\text {new }}$ is the value of moisture needed for the updated height $\left(z_{i}\right)_{\text {new }}$ with respect to the original $\left(q_{t}^{\mathrm{BL}}\right)_{\text {old }}$. For varying $\left.z_{i}\right|_{h}, h$ is constant and $\Delta z_{b}=\Delta z_{i}=$ $\left(z_{i}\right)_{\text {new }}-\left(z_{i}\right)_{\text {old }}$ is the change in cloud thickness from the reference case, with $\left(z_{i}\right)_{\text {old }}$ the reference case inversionbase height. $T_{b}$ is the temperature at the original cloudbase height.

Similarly, the motivation for (iii) is to assess the changes of $h$ without the effects of varying $z_{i}$. We refer to this case as varying $\left.h\right|_{z i}$, and the adjusted $q_{t}^{\mathrm{BL}}\left(\left.h\right|_{z_{i}}\right)$ is obtained with Eq. (3), taking $\Delta z_{b}=-\Delta h=(h)_{\text {old }}-$ $(h)_{\text {new }}$ because $z_{i}$ is constant. Here, $(h)_{\text {old }}$ is the cloud thickness for the reference case and $(h)_{\text {new }}$ is the updated cloud thickness.

\section{Results and discussion}

\section{a. Data statistics and correlations}

We present a description of the most important intercorrelations within the dataset, which is crucial for understanding the results of the impacts when all variables covary. Table 1 shows the main statistics, including diagnostic variables from the MLM (cloud-base height $z_{b}$, cloud thickness $h$, inversion jump of virtual potential temperature $\Delta_{i} \theta_{v}$, and liquid water path LWP) and for the well-mixed profiles before and after STI. In the remainder of this section, we describe the main correlations (Fig. 4), distinguished by the nature of their relationship (seasonal trends, initial conditions, and boundary forcings). We emphasize that initial conditions are prior to sunrise and represent both coastal land and ocean conditions.

Given the large number of variables, principal component analysis (PCA) would seem to be a relevant tool. We do not report PCA results for this dataset because the reduction of dimensions is limited (it takes 10 variables to explain $90 \%$ of the variance) and the resulting parameter space is nonphysical.

\section{1) VARIABLES AFFECTED BY SEASONAL TRENDS}

Our dataset includes measurements taken between May and September, a time span that is long enough to 
TABLE 1. Statistics for the variables considered in the MLM initialization and complementary variables for describing the cloudy states, corresponding to the 195 available days. Original and STI-derived states are included.

\begin{tabular}{|c|c|c|c|c|c|c|}
\hline Variable & Units & Min & $\operatorname{Max}$ & Median & Mean & $\mathrm{SD}$ \\
\hline \multicolumn{7}{|c|}{ Original values } \\
\hline$q_{t}^{\mathrm{BL}}$ & $\mathrm{g} \mathrm{kg}^{-1}$ & 7.557 & 16.38 & 11.51 & 11.52 & 1.494 \\
\hline$\Delta_{i} q_{t}$ & $\mathrm{~g} \mathrm{~kg}^{-1}$ & -10.89 & -2.513 & -7.246 & -7.091 & 1.758 \\
\hline$q_{t}^{3 \mathrm{~km}}$ & $\mathrm{~g} \mathrm{~kg}^{-1}$ & 0.5531 & 12.59 & 4.217 & 4.424 & 2.278 \\
\hline$\theta_{l}^{\mathrm{BL}}$ & $\mathrm{K}$ & 287.9 & 298 & 291.8 & 291.7 & 1.697 \\
\hline$\Delta_{i} \theta_{l}$ & $\mathrm{~K}$ & 5.679 & 19.53 & 11.04 & 11.3 & 2.538 \\
\hline \multicolumn{7}{|c|}{ STI modified values } \\
\hline$q_{t}^{\mathrm{BL}}$ & $\mathrm{g} \mathrm{kg}^{-1}$ & 7.557 & 16.38 & 11.38 & 11.43 & 1.532 \\
\hline$\Delta_{i} q_{t}$ & $\mathrm{~g} \mathrm{~kg}^{-1}$ & -10.82 & -2.513 & -7.243 & -7.073 & 1.749 \\
\hline$q_{t}^{3 \mathrm{~km}}$ & $\mathrm{~g} \mathrm{~kg}^{-1}$ & 0.2555 & 12.59 & 4.077 & 4.358 & 2.321 \\
\hline$\theta_{l}^{\mathrm{BL}}$ & $\mathrm{K}$ & 288.1 & 298 & 291.8 & 291.7 & 1.692 \\
\hline$\Delta_{i} \theta_{l}$ & $\mathrm{~K}$ & 5.679 & 19.53 & 11.04 & 11.32 & 2.531 \\
\hline \multicolumn{7}{|c|}{ Unchanged values } \\
\hline$z_{i}$ & $\mathrm{~m}$ & 181 & 1493 & 587 & 597.8 & 190.8 \\
\hline$z_{i t}$ & $\mathrm{~m}$ & 322 & 1602 & 805 & 843.6 & 191.7 \\
\hline$\theta_{l}^{3 \mathrm{~km}}$ & $\mathrm{~K}$ & 304.8 & 324.4 & 317 & 316.8 & 3.391 \\
\hline $\bar{u}$ & $\mathrm{~m} \mathrm{~s}^{-1}$ & 1.543 & 4.148 & 2.458 & 2.531 & 0.4971 \\
\hline SLP & $\mathrm{hPa}$ & 1008 & 1017 & 1012 & 1013 & 1.716 \\
\hline$D$ & $10^{-6} \mathrm{~s}^{-1}$ & -3.167 & 14.11 & 3.442 & 3.696 & 2.865 \\
\hline Bo & - & 0.2293 & 1.563 & 1.053 & 1.047 & 0.1778 \\
\hline $\mathrm{SW}_{i}$ & $\mathrm{~W} \mathrm{~m}^{-2}$ & 827.4 & 989.5 & 977.5 & 961.5 & 33.75 \\
\hline LHF & $\mathrm{W} \mathrm{m}^{-2}$ & 8.385 & 75.18 & 31.82 & 32.54 & 11.44 \\
\hline SHF & $\mathrm{W} \mathrm{m}^{-2}$ & 1.222 & 19.24 & 8.661 & 8.829 & 3.312 \\
\hline SST & $\mathrm{K}$ & 290.6 & 298.7 & 295 & 294.7 & 1.891 \\
\hline$T_{\text {sky }}$ & $\mathrm{K}$ & 255.7 & 291 & 272.4 & 272.2 & 6.608 \\
\hline \multicolumn{7}{|c|}{ Derived values } \\
\hline$z_{b}$ & $\mathrm{~m}$ & 159 & 1139 & 448 & 458.9 & 142.3 \\
\hline$h$ & $\mathrm{~m}$ & 4 & 423 & 125 & 138.9 & 81.53 \\
\hline$\Delta_{i} \theta_{v}$ & $\mathrm{~K}$ & 4.607 & 18.48 & 9.281 & 9.525 & 2.41 \\
\hline LWP & $\mathrm{g} \mathrm{m}^{-2}$ & 0.402 & 202.8 & 20.36 & 32.12 & 34.96 \\
\hline
\end{tabular}

show seasonal patterns that influence the correlation between some variables (no detrending is performed in this dataset). While solar irradiance above the cloud $\mathrm{SW}_{i}$ varies during the year, peaking on June 21, the set of temperature variables SST, $\theta_{l}^{\mathrm{BL}}$, and $T_{\text {sky }}$ peak in early August. The time lag between $\mathrm{SW}_{i}$ and the temperature variables is influenced by the seasonal pattern of SST, which in turn is affected by the oceanic upwelling that is stronger during June and July for Southern California (Clemesha et al. 2016) as well as the thermal inertia of the ocean. The time lag is long enough to cause a negative correlation between temperatures and $\mathrm{SW}_{i}$ as shown in Fig. 4a.

The strong correlation between SST and $\theta_{l}^{\mathrm{BL}}$ results from the strong influence of ocean SST on the early morning coastal air temperature through horizontal advection.

\section{2) VARIABLES THAT DETERMINE INITIAL CONDITIONS}

The initial state, prior to sunrise, comprises $z_{i}, q_{t}(z)$, and $\theta_{l}(z)$, which together determine $h$. By definition, a warmer $\mathrm{ABL}$ that is cloudy is at (in-cloud) or near (below-cloud) saturation and can contain more water due to the Clausius-Clapeyron relationship; this makes $\theta_{l}^{\mathrm{BL}}$ and $q_{t}^{\mathrm{BL}}$ highly correlated. Conversely, conditions that are warm and dry (causing a negative correlation) are less likely to sustain a cloud and are therefore underrepresented in the dataset.

Inversion-base height $z_{i}$ is strongly anticorrelated with $q_{t}^{\mathrm{BL}}$; a deeper ABL is associated with lower temperature at the inversion base, requiring less water content to be present to saturate and form a cloud. Entrainment also supports this relationship, as prolonged or stronger entrainment can result in deeper ABLs and a lower $q_{t}^{\mathrm{BL}}$. Interestingly, the relationship between the primary $3 \mathrm{ABL}$ variables $q_{t}^{\mathrm{BL}}, z_{i}$, and $\theta_{l}^{\mathrm{BL}}$ is observed to be linear $\left(R^{2}\right.$ of linear fit is $0.945 ;$ Fig. $\left.7 \mathrm{a}\right)$ and closely follows saturation conditions (see appendix E). Although a linear relationship exists, only two of the three pairs are correlated, as $z_{i}$ and $\theta_{l}^{\mathrm{BL}}$ do not correlate; therefore, $q_{t}^{\mathrm{BL}}$ acts like a dependent variable.

Cloud thickness $h$ is defined as the difference between cloud top $z_{i}$ and cloud base $z_{b}$ heights. One might expect 

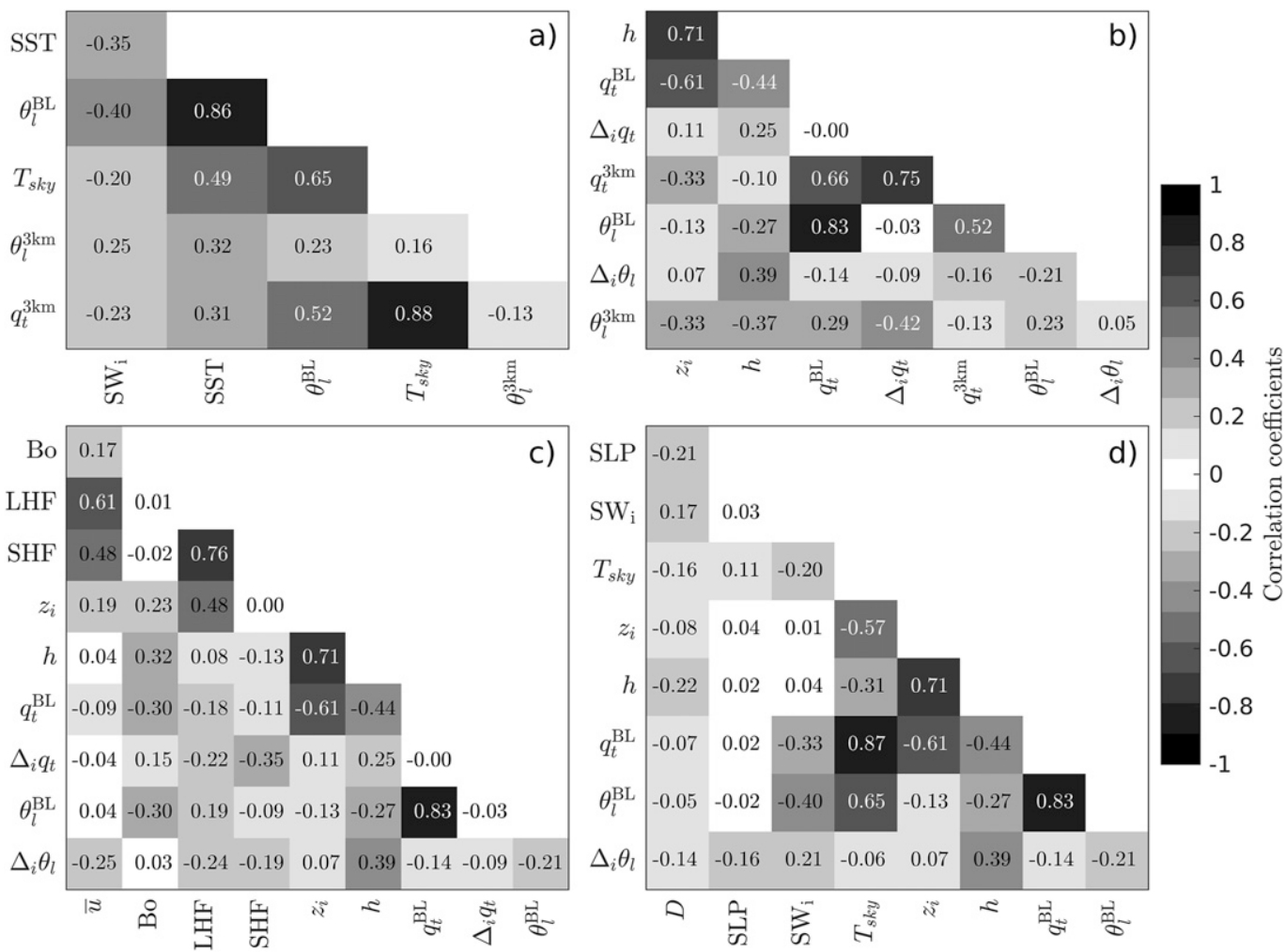

FIG. 4. Correlation coefficient matrix for variables spanning the 195 selected days grouped by their relationship: (a) seasonal trends, (b) initial conditions, (c),(d) boundary forcings divided into two figures for easier presentation-(c) wind and surface fluxes variables and (d) large-scale and radiation parameters. The sign is representative of each correlation coefficient.

lower cloud base to mean greater cloud thickness, but instead variations in cloud thickness are dominated by variations in ABL-top height (deeper ABLs have more room for thick clouds). The correlation between $z_{i}$ and $q_{t}^{\mathrm{BL}}$ causes thicker clouds to be strongly associated with smaller $q_{t}^{\mathrm{BL}}$. Cloud thickness is also strongly correlated with $\Delta_{i} \theta_{l}$ because a stronger temperature inversion limits the entrainment of drier and warmer air into the ABL, which thins the cloud. Figure $4 \mathrm{~b}$ shows that both $z_{i}$ and $\Delta_{i} \theta_{l}$ influence $h$. Although the linear correlation coefficient is only 0.61 , both variables combined explain nearly all the variance in $h$ : ABLs with lower (higher) tops and weaker (stronger) capping inversions are related to thinner (thicker) clouds. Note that $\Delta_{i} \theta_{l}$ and $z_{i}$ are not correlated in our dataset (Fig. 4). While this may seem counterintuitive as strong LTS has been linked to shallower ABLs (Klein and Hartmann 1993), LTS not only depends on $\Delta_{i} \theta_{l}$ but also on $z_{i}$. Following Wood and Bretherton (2006), the correlation coefficients of $z_{i}$ and $\Delta_{i} \theta_{l}$ with LTS are -0.48 and 0.84 , respectively.

For the tropospheric quantities, $q_{t}^{3 \mathrm{~km}}$ correlates with $q_{t}^{\mathrm{BL}}$ : a smaller $q_{t}$ in the $\mathrm{ABL}$ is related to a smaller $q_{t}$ above. The same logic explains the correlation between $\theta_{l}^{3 \mathrm{~km}}$ and $\theta_{l}^{\mathrm{BL}}$.

\section{3) VARIABLES THAT DETERMINE BOUNDARY FORCINGS}

Here, correlations between parameters that specify the boundary forcing of the ABL from above and below are described. Large-scale subsidence, represented by the horizontal divergence $D$, is weakly correlated with $z_{i}$ even though subsidence pushes the ABL top down. At -0.08 , the correlation coefficient is small, which could be related to errors in estimating divergence, or to the different values of entrainment that also affect $z_{i}$, or due to time lags/phase shifts between when changes in $D$ affect $z_{i}$, thus weakening the correlation between the two variables. From Myers and Norris (2013), we would expect subsidence to also influence $\Delta_{i} \theta_{l}$, but the correlation between $D$ and $\Delta_{i} \theta_{l}$ is weak. This disagreement may be explained also by the variables being out of phase and by the exclusive use of well-mixed Sc-capped ABLs in our dataset [vs all ABLs in Myers and Norris (2013)], since other ABL types tend to be associated with smaller $D$ and smaller $\Delta_{i} \theta_{l}$. 
Surface fluxes affect both temperature and moisture in the ABL. Over the ocean, LHF and SHF correlate with $\bar{u}$ by definition [Eqs. (C8) and (C9)]. LHF is correlated with $z_{i}$ while SHF is not. A larger LHF was also related to a larger $z_{i}$ in (Bretherton and Wyant 1997) probably because a larger LHF is related to a smaller $q_{t}^{\mathrm{BL}}$ (by definition), which in turn correlates to a larger $z_{i}$. In contrast, SHF depends on $\theta_{l}^{\mathrm{BL}}$, which is not correlated to $z_{i}$.

Over land, Bo is negatively correlated to $q_{t}^{\mathrm{BL}}$ as an ABL with stronger surface latent heat fluxes causes both a larger $q_{t}^{\mathrm{BL}}$ and a smaller Bo. Secondary variable correlations $\left(q_{t}^{\mathrm{BL}}\right.$ to $\theta_{l}^{\mathrm{BL}}$ and $\left.z_{i}\right)$ explain the correlation of Bo to $\theta_{l}^{\mathrm{BL}}$ and $z_{i}$.

The last set of forcings are the radiative fluxes. For the shortwave portion, the yearly variations of solar irradiance causes $\mathrm{SW}_{i}$ to be anticorrelated with temperature metrics [section $3 \mathrm{a}(1)]$. For the longwave portion, $T_{\text {sky }}$ is correlated with $q_{t}^{3 \mathrm{~km}}$ due to the longwave absorption and emission by water molecules above the cloud (Fig. C1a). Secondary variable correlations $\left(q_{t}^{3 \mathrm{~km}}\right.$ to $q_{t}^{\mathrm{BL}}$ and $\left.z_{i}\right)$ explain the correlation of $T_{\text {sky }}$ with $q_{t}^{\text {BL }}$ and $z_{i}$.

\section{b. Dissipation time dependence}

We now review the results of the sensitivity analyses of modeled dissipation time, defined as the time when cloud thickness $h$ becomes zero. The main focus of this section is to compare the covariability results of the 195 simulated days to the single-variable changes as well as previous studies. The discussion is subdivided into initial conditions and forcing parameters.

The covariability results for the 195 MLM simulations are shown in Fig. 5. The $t_{\text {diss }}$ histogram (Fig. 5a) shows that clouds either dissipate before 1300 LST or persist for the whole day. We refer to these two categories as dissipating and persisting cases, respectively, so $t_{\text {diss }}$ is defined for dissipating clouds only. Some of the variables influence $t_{\text {diss }}$, while others differ markedly between dissipating and persisting cases, and some show unclear trends or nonmonotonic tendencies. Figures $5 \mathrm{~b}-\mathrm{r}$ show the top 17 trends with linear fits for $t_{\text {diss }}$ with $R^{2}>0.02$ or with a noticeable difference between persisting and dissipating cases. Dissipation time is strongly related to $h, z_{i}$, LWP, $q_{t}^{\mathrm{BL}}$, $\Delta_{i} \theta_{l}, T_{\text {sky }}$, and oceanic SHF; while $\bar{u}$, Bo, and $D$ show weaker trends.

The results for the single-variable changes from an idealized reference case while holding all other variables constant are shown in Fig. 6, where simulated dissipation time for the land column is plotted against the variables' $Z$ score (subtracting observed mean and dividing by the standard deviation) for ease of comparison. The idealized reference case corresponds to a coastal cloud that dissipates around 0800 LST (continuous line in Fig. F1 in appendix F).

\section{1) Initial ABL state}

The initial state of the ABL affects the dissipation time more than the forcing parameters. The components of the initial state are $z_{i}, q_{t}^{\mathrm{BL}}$, and $\theta_{l}^{\mathrm{BL}}$, which have an intricate relationship [section $3 \mathrm{a}(2)$ and Fig. 7], and together determine $h$. Although $h$ is not an explicit input variable to the MLM, we include it in the analysis because of its strong trend, the fact that it is readily observable, and its importance for entrainment and radiation.

For all the approaches considered, $h$ has the most robust relationship with $t_{\text {diss }}$, followed by $z_{i}$. Thicker clouds or deeper ABLs either dissipate later or persist for the whole day. Similar to marine Sc (Burleyson and Yuter 2015), clouds that are thicker at dawn can withstand more solar heating and delay dissipation. For both $h$ and $z_{i}$, covariability weakens the single-variable change trends on $t_{\text {diss }}$ (Figs. 5e,b and 6a) because the independent effects are diminished by the effects of the variables that covary with them, such as $q_{t}^{\mathrm{BL}}$. For $z_{i}$, the covariability trend is more similar to the experiment where cloud thickness is held constant by varying $\left.z_{i}\right|_{h}$ together with $q_{t}^{\mathrm{BL}}$ (Fig. 6b). This means that even when we control for the strong effects of $h$, other variables with weaker independent trends also impact the final trend for $z_{i}$. The trends for $h$ and $z_{i}$ imply a strong trend for LWP as well (Fig. 5q). Since $z_{i}$ and $h$ are correlated, we analyze the trend of $t_{\text {diss }}$ with respect to both variables. Figure $8 \mathrm{~b}$ shows that dissipation time varies with both $h$ and $z_{i}$, but it is more strongly correlated with cloud thickness.

While colder ABLs are related to later dissipation, as expected, moister ABLs dissipate earlier with covariability. For $\theta_{l}^{\mathrm{BL}}$, the trend with covariability (Fig. 5c) is weaker than for the single-variable changes (Fig. 6a), and for $q_{t}^{\mathrm{BL}}$, the trend with covariability (Fig. 5d) is completely opposite to the single-variable changes (Fig. 6a). This seeming contradiction is actually in agreement with the strong correlations observed between larger $q_{t}^{\mathrm{BL}}$ and both lower $h$ and $z_{i}$ and larger $\theta_{l}^{\mathrm{BL}}$, which shorten cloud lifetime.

The fact that $q_{t}^{\mathrm{BL}}$ does not dominate the trend with covariability also agrees with the linear dependence of $q_{t}^{\mathrm{BL}}$ on $z_{i}$ and $\theta_{l}^{\mathrm{BL}}$ [section $\left.3 \mathrm{a}(2)\right]$, and with the cloud thickness regulation feedback. Cloud thickness is regulated toward an equilibrium state in that thicker clouds enhance cloud radiative cooling and entrainment, which in turn thin the cloud and regulate $h$ (Zhu et al.2005). At nighttime, thinner clouds will experience weaker entrainment due to the regulating feedback, keeping the 

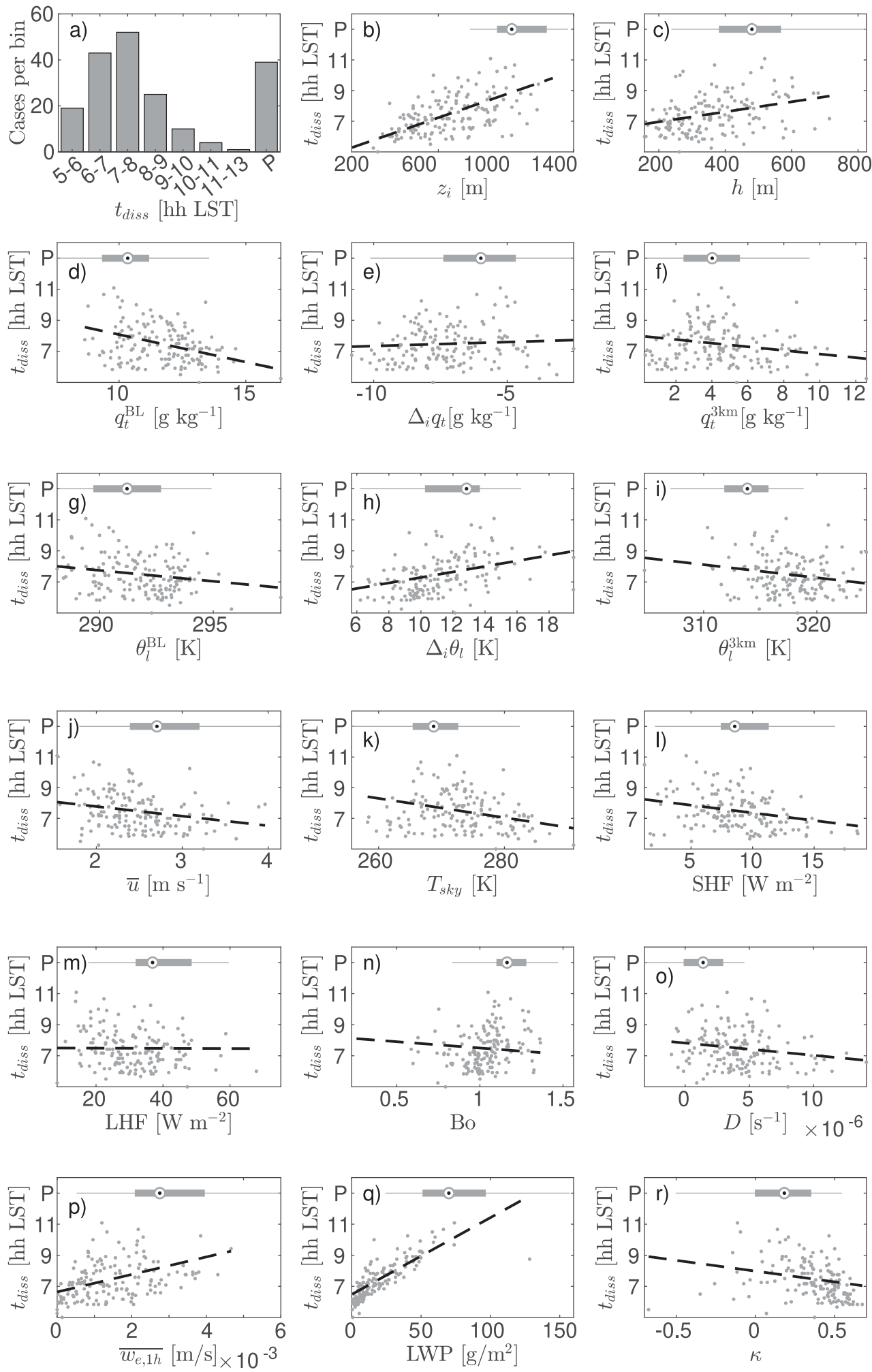

FIG. 5. (a) The distribution of dissipation time $t_{\text {diss }}$ over coastal land. (b)-(r) The effects of all variables on $t_{\text {diss }}$ for all 195 days. Raw data (gray dots) and a linear fit (dashed black) are shown for the dissipating cases. Distributions (gray box plots) are shown for the persisting cases (marked as $\mathrm{P}$ in the $t_{\text {diss }}$ axis), with boxes marking the 25 th and 75 th percentiles, a circle marking the median, and lines extending between the minimum and maximum values (excluding outliers). 

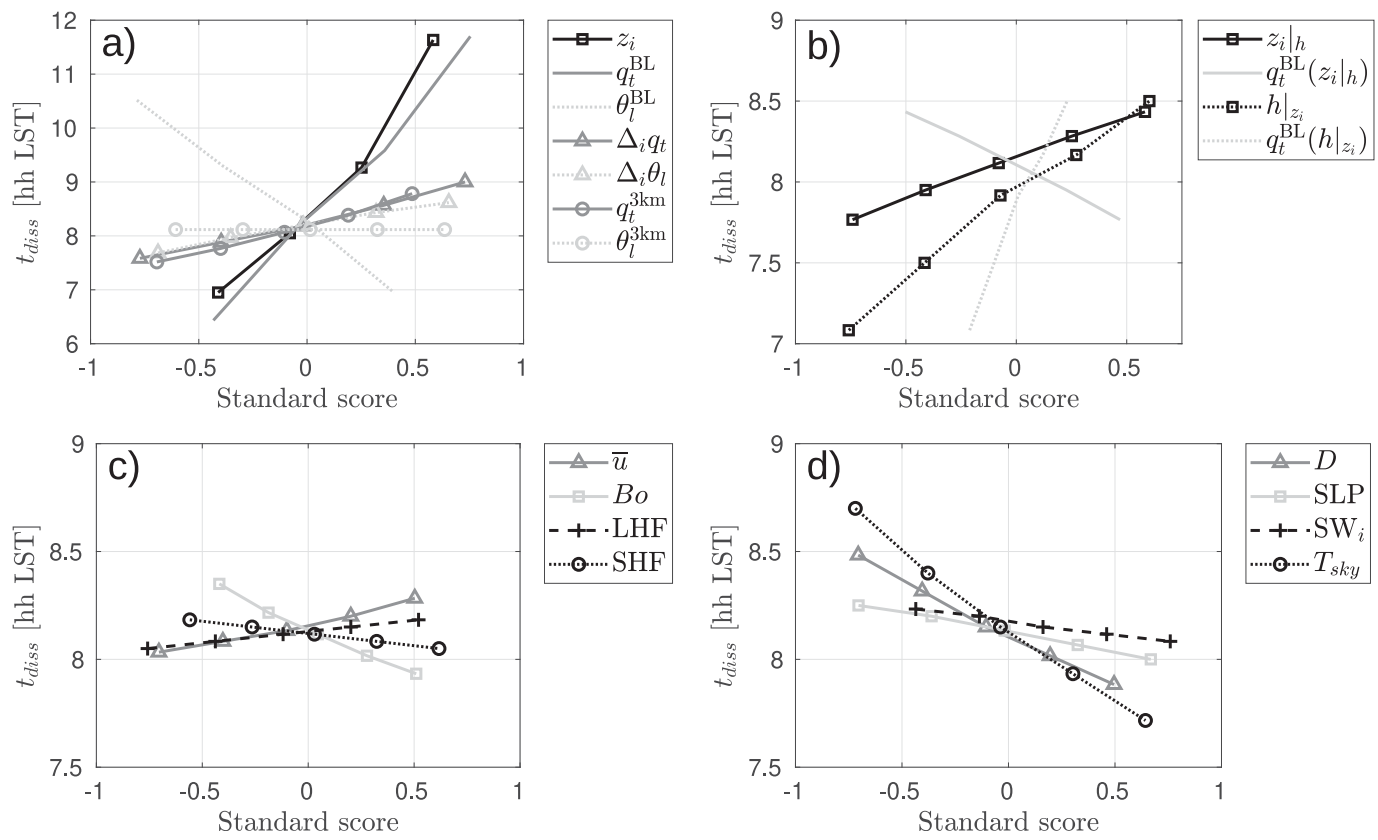

FIG. 6. Effect on dissipation time over land of the change of a single variable for the idealized reference case of observed medians. Variables are shown in terms of their $Z$ score, computed by subtracting the observed mean and dividing by the observed standard deviation. (a) Changes of initial-condition variables one at a time, (b) changes of $\left.z_{i}\right|_{h}$ to maintain constant cloud thickness and the corresponding values of $q_{t}^{\mathrm{BL}}\left(\left.z_{i}\right|_{h}\right)$, and changes of $\left.h\right|_{z_{i}}$ maintaining constant $z_{i}$ and the corresponding changes of $q_{t}^{\mathrm{BL}}\left(\left.h\right|_{z_{i}}\right)$, (c) changes in advection and land surface forcing variables, and (d) changes in radiative, subsidence, and SLP variables. Some trends include less than five points as clouds were not present for some configurations.

ABL moister and shallower and supporting the negative correlation between $z_{i}$ and $q_{t}^{\mathrm{BL}}$, and between $h$ and $q_{t}^{\mathrm{BL}}$. For these initially thin clouds experiencing reduced entrainment, we expect a shorter cloud lifetime, which agrees with the trend of weaker first hour initial entrainment rates $\overline{w_{e, 1 h}}$ and earlier $t_{\text {diss }}$ (Fig. 5p). Last, Fig. 8a visually shows the lack of dominance of $q_{t}^{\mathrm{BL}}$ on $t_{\text {diss }}$ when compared to $z_{i}$ : the gradient of dissipation time, as well as the region of persisting clouds, are more strongly correlated with $z_{i}$ than $q_{t}^{\mathrm{BL}}$, meaning that the trend between $q_{t}^{\mathrm{BL}}$ and $t_{\mathrm{diss}}$ in Fig. $5 \mathrm{~d}$ is a consequence of the anticorrelation between $z_{i}$ and $q_{t}^{\mathrm{BL}}$.

\section{2) INVERSION JUMPS AND FREE-TROPOSPHERIC CONDITIONS}

While the inversion jumps and free-tropospheric state are part of the initial conditions, we analyze them separately because they represent the interaction between
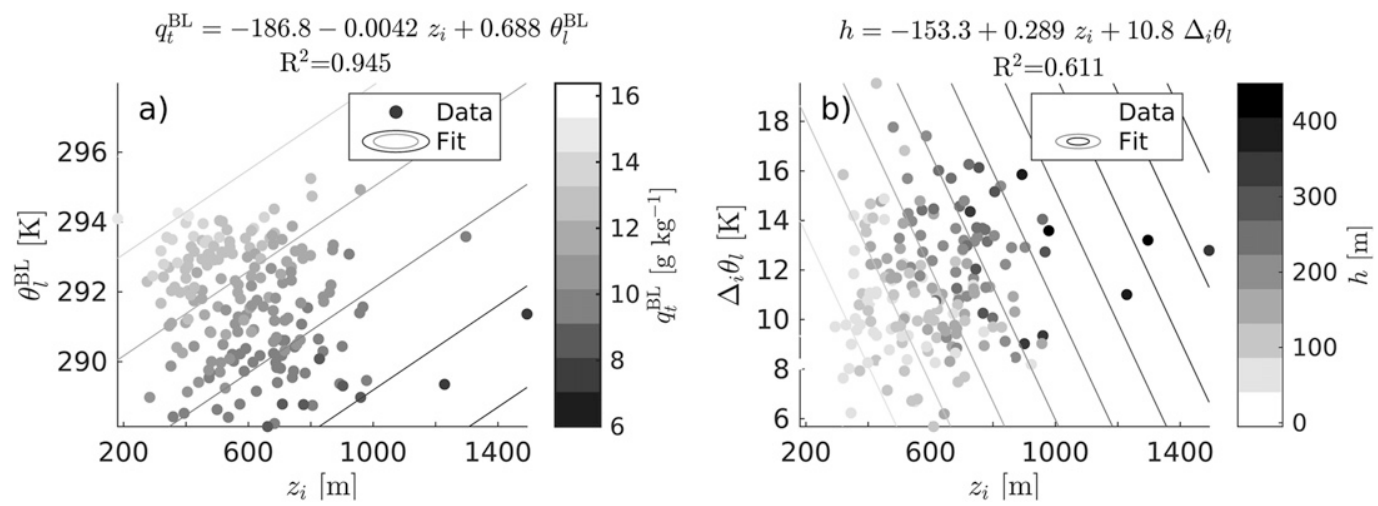

FIG. 7. Relationships between triads of variables: (a) $q_{t}^{\mathrm{BL}}$ in the plane described by $z_{i}$ and $\theta_{l}^{\mathrm{BL}}$ and (b) $h$ in the plane described by $z_{i}$ and $\Delta_{i} \theta_{l}$. Gray dots are data points and contours are the best linear fit per the fit equation shown above each panel. 

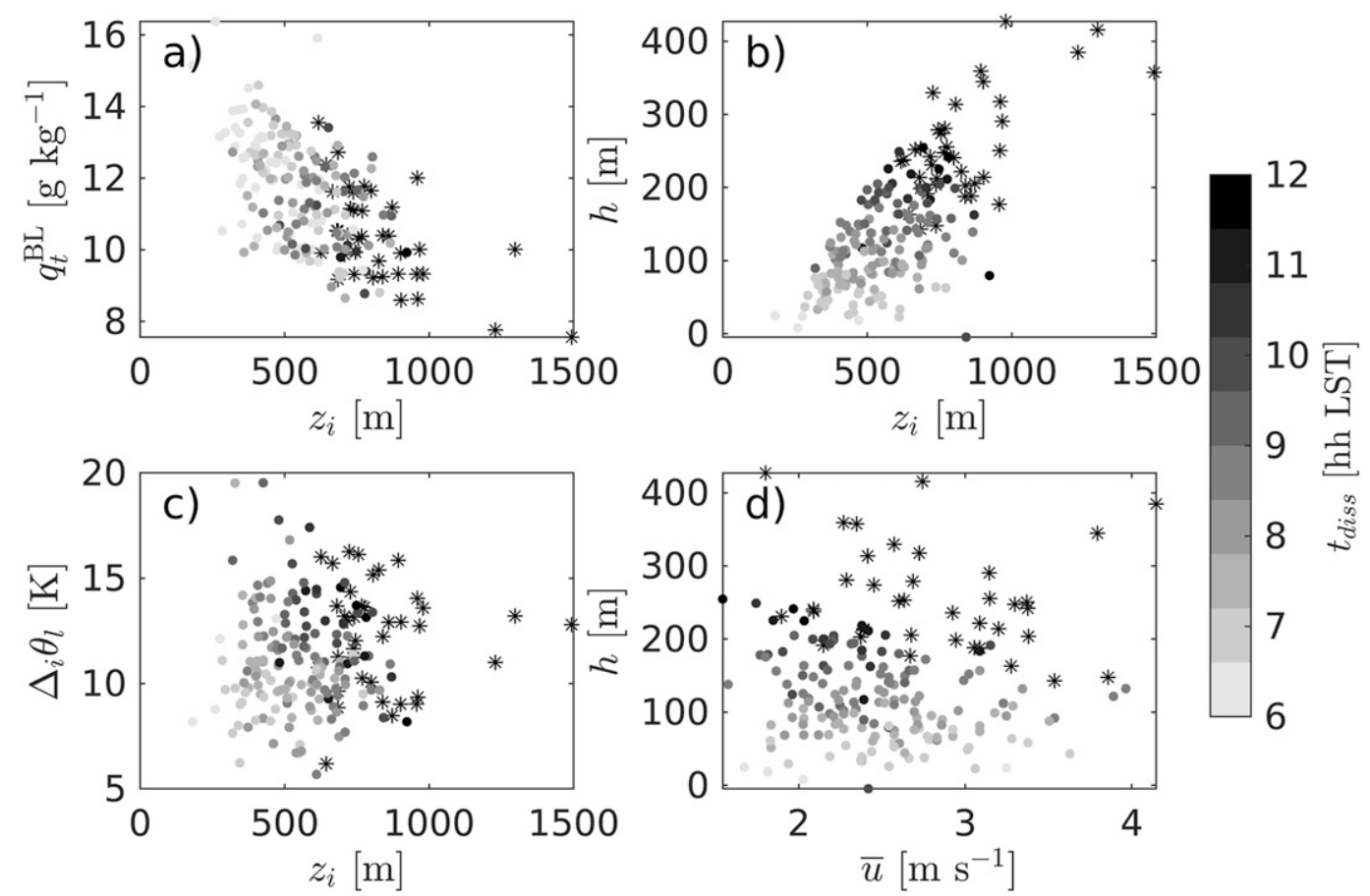

FIG. 8. Two-dimensional variable spaces for (a) $z_{i}$ and $q_{t}^{\mathrm{BL}}$, (b) $z_{i}$ and $h$, (c) $z_{i}$ and $\Delta_{i} \theta_{l}$, and (d) $\bar{u}$ and $h$. Data are classified by cases that persist for the whole day (black asterisks, 38 cases) and cases that dissipate during the day (dots colored by dissipation time, 157 cases).

the $\mathrm{ABL}$ and free troposphere, rather than the $\mathrm{ABL}$ state. Stronger temperature inversion jumps $\Delta_{i} \theta_{l}$ and weaker moisture inversion jumps $\Delta_{i} q_{t}$ (moister troposphere) delay dissipation time (Figs. 5f,g), in agreement with most previous studies.

The effect of stronger temperature inversion jumps $\Delta_{i} \theta_{l}$ agrees with the result for the single-variable changes (Fig. 6a) for our reference case. Ma et al. (2018) obtained a $\Delta_{i} \theta_{l}$ trend that opposed ours and that of $\mathrm{Xu}$ and Xue (2015), and argued that the impacts of the temperature inversion jump might depend on the reference case selected. There are competing effects of $\Delta_{i} \theta_{l}$ : while a stronger temperature inversion jump reduces the entrainment rate, it also means that the entrained air is warmer. Mathematically, the net warming heat flux is the product of a reduced entrainment rate and a stronger inversion jump, and the direction of the effect for the product could vary for different conditions [Eq. (B15)]. For our reference case, the diminished entrainment rate dominates the over the warmer entrained air, delaying the dissipation by maintaining the ABL moister and colder over land and ocean (Fig. F1a). Our results with covariability support the trend of Xu and Xue (2015) and van der Dussen et al. (2015), as well as the trend of increased cloudiness with stronger $\Delta_{i} \theta_{l}$ in previous climate studies (Seethala et al. 2015; Klein and Hartmann 1993; Klein et al. 1995; Wood and Bretherton 2006).
Nonetheless, we note that persisting clouds do not predominantly exhibit stronger inversion jumps.

As was the case with $h$, the influence of $\Delta_{i} \theta_{l}$ on $t_{\text {diss }}$ is not dominated by $z_{i}$. This is evident in the twodimensional space of $z_{i}$ jointly with $\Delta_{i} \theta_{l}$. Figure $8 \mathrm{c}$ shows that earlier dissipation (persisting clouds) occurs for shallow (deeper) ABLs under a weak (strong) inversion, which also corresponds to the conditions for thinner clouds shown in Fig. $4 \mathrm{~b}$.

For moisture, weaker inversion jumps $\Delta_{i} q_{t}$ (relatively moister free troposphere) are linked to persisting clouds, although dissipation time (as a continuous variable) is not strongly correlated to $\Delta_{i} q_{t}$ (Fig. $5 \mathrm{~g}$ ). The trend is consistent with the single variations due to reduced entrainment drying (Fig. 6a), in agreement with the LWP responses reported by van der Dussen et al. (2015), Xu and Xue (2015), and Ma et al. (2018).

At first glance, the covariability trends of $\Delta_{i} q_{t}$ and $q_{t}^{3 \mathrm{~km}}$ seem contradicting: weaker $\Delta_{i} q_{t}$ (relatively moister free troposphere) and also lower $q_{t}^{3 \mathrm{~km}}$ (drier free troposphere) lead to persisting clouds (Figs. 5g,h). However, a weaker $\Delta_{i} q_{t}$ is only a free troposphere that is similar in moisture to the ABL, and not necessarily a moister free troposphere. Thus, a very dry free troposphere can have a weak inversion jump if the ABL is also dry. Nevertheless, the trend of a dry troposphere extending dissipation time is still unexpected since it opposes the 
single-variable changes (Fig. 6a). The strong correlations between drier $q_{t}^{3 \mathrm{~km}}$ to higher $z_{i}$ and lower $T_{\text {sky }}$, both of which extend cloud lifetime, explain the trend. Previous studies have related a moister free troposphere to reduced cloudiness (Dal Gesso et al. 2014; Seethala et al. 2015), where the latter (correctly) speculated that correlations rather than physical processes are responsible for the trend.

The combined effects of moisture and temperature inversion jumps have been studied for the cloud-top entrainment instability (CTEI), a process that can trigger cloud dissipation (Deardorff 1980; Kuo and Schubert 1988; van der Dussen et al. 2014; Xu and Xue 2015). Even though the stability parameter criterion $\kappa \geq 0.23$ was found to be insufficient to predict the CTEI, Fig. 5r shows a trend between larger $\kappa$ and earlier dissipation, suggesting that CTEI could be contributing to cloud dissipation for larger $\kappa$. Nevertheless, the great dispersion precludes us from stating this conclusively $\left(R^{2}=0.03\right)$.

Similarly to $q_{t}^{3 \mathrm{~km}}, \theta_{l}^{3 \mathrm{~km}}$ has a stronger effect with covariability than in the single-variable changes (Figs. $5 \mathrm{i}$ and 6a). The enhanced effect of $\theta_{l}^{3 \mathrm{~km}}$ can be explained by the strong correlation to $\theta_{l}^{\mathrm{BL}}$.

\section{3) SEA-BreEze ADVECTION}

Since sea-breeze advection is crucial in extending the lifetime of coastal Sc (Ghonima et al. 2016), a robust trend between $\bar{u}$ and $t_{\text {diss }}$ is expected, as shown by the single-variable changes (Fig. 6c). In actuality, the trends with covariability show $\bar{u}$ exhibiting a nonlinear behavior where larger wind speeds are associated with both persisting clouds and early dissipation time (Fig. 5j).

The nonlinear trend of $\bar{u}$ is not related to the physics, but it is caused by a sampling issue. To explain this misleading trend, we look at the influence of initial cloud thickness on the relationship between $\bar{u}$ and $t_{\mathrm{diss}}$. Figure $8 \mathrm{~d}$ shows first that $h$ dominates the dependence of dissipation time in the $\bar{u}$ and $h$ space. Second, separating analyses for thick $(h>150 \mathrm{~m})$ and thin clouds is enlightening. Thicker clouds persist with larger $\bar{u}$, as expected, and the critical wind speed for clouds to persist decreases with greater initial cloud thickness. For thinner clouds, the dissipation time is not affected by $\bar{u}$. Since the persisting clouds are not part of the trend lines in Fig. 7, a misleading anticorrelation of wind speed and dissipation time is observed. This analysis suggests that advection is irrelevant for thin clouds as they already dissipate before the onset of advection around 0700 LST. Advection does play an important role for thicker clouds that survive through the weak advection period, which then benefit from the cooling associated with stronger advection. This effect was not observed by Ghonima et al. (2016) as they only analyzed two reference cases with the presence or absence of sea breeze.

Another aspect that could cause our results to deviate from real observations is the wind speed input for the MLM. For ease of comparison, we have assumed that the wind speed for all 195 days has the same diurnal variation (i.e., the onset of sea breeze is fixed, but the magnitude changes). However, we speculate that the timing of the sea-breeze onset may be as or more important than the wind speed magnitude. By 0800 LST, when the wind speed increases in our simulation (Fig. C1b), 116 days are already clear or have clouds that are already so thin that the heat input from solar radiation dominates over cooling from horizontal advection. For these early morning dissipation cases, the wind speed is irrelevant. This timing dependence was also mentioned by Burleyson and Yuter (2015) for marine Sc, as cloud breakup rates strengthen near noon.

\section{4) SURFACE FLuXES}

For coastal Sc clouds, both the surface fluxes over the ocean and over land can affect the cloud evolution. A larger SHF over the ocean is linked to earlier dissipation time, agreeing with previous studies for marine Sc (McMichael et al. 2019; Chlond and Wolkau 2000). The effect of SHF under covariability is greater than for the single-variable changes (Figs. 5k and 6c). In contrast, the influence of LHF on $t_{\text {diss }}$ is weak with covariability, despite the existence of persistent clouds for larger LHF (Fig. 5l) supporting the trend of the single-variable changes (Fig. 6c). This difference between the effect of SHF and LHF suggests that the importance of the ocean fluxes, which influences coastal clouds through advection, may be greater for temperature than for moisture, agreeing with Ghonima et al. (2016).

Over land, the influence of Bo on dissipation time does not show a strong trend when covariability is considered, but persistent cases are related to higher Bo (Fig. 5m), contradicting Ghonima et al. (2016) and the trends of single-variable changes. This unexpected effect is a consequence of the correlation between Bo and $q_{t}^{\mathrm{BL}}$.

\section{5) LARGE-SCALE FORCINGS}

Subsidence is known to be of great importance for the evolution of Sc clouds. Stronger $D$ reduces cloud lifetime by thinning the cloud from the top, and the clouds that persist have lower $D$ (Fig. 5n), agreeing with the single-variable changes (Fig. 6d), as well as the response in LWP in previous sensitivity studies (McMichael et al. 2019; Ma et al. 2018; van der Dussen et al. 2016; Noda et al. 2014; Blossey et al. 2013) and 
the response in cloudiness for independent changes of subsidence (Myers and Norris 2013).

Aside from subsidence, SLP is an indicator of the synoptic conditions over the coast of California. Although there is not a robust impact of SLP on $t_{\text {diss }}$ with covariability (not shown), we note that the physical impact of a smaller SLP yields later $t_{\text {diss }}$ because-for constant $\theta_{l}^{\mathrm{BL}}-\mathrm{a}$ colder temperature profile is needed to balance the change in pressure, resulting in a thicker cloud.

\section{6) RADIATIVE FORCINGS}

We have two radiation parameters of importance for dissipation of coastal clouds representing radiative cooling and solar heating. Stronger radiative cooling, represented by a lower $T_{\text {sky }}$, delays dissipation with the most robust trend of all the forcing parameters (Fig. 5o). This effect agrees with the single-variable changes (Fig. 6d) and previous studies (Kopec et al. 2016; Chlond and Wolkau 2000).

For the solar heating, $\mathrm{SW}_{i}$ shows no clear trend with $t_{\text {diss }}$ under covariability (not shown). Meanwhile, the effect observed for single-variable changes is that increased heating shortens cloud lifetime (Fig. 6d), as the additional heating of the cloud and the land surface accelerates dissipation. Although $\mathrm{SW}_{i}$ was found to strongly influence the rate of cloud breakup for marine clouds (Burleyson and Yuter 2015), that effect may be reduced by the dominance of other factors such as ABL depth and cloud thickness.

\section{c. Summary, quantification, and discussion of dissipation trends}

Most of the impacts of different variables on cloud dissipation time over land were either diminished or increased when considering covariability, while others were unexpected due to the correlations among parameters related to forcings and initial conditions. In this section, we summarize and quantify the most robust trends when all variables covary and compare them to the trends resulting from changes in a single variable when all others are held constant.

The trends are expressed as $\delta \psi / \delta t_{\text {diss }}$, quantifying how much change in a variable $\psi$ is needed to delay $t_{\text {diss }}$ by $1 \mathrm{~h}$. Thus, the greater the number, the less sensitive $t_{\text {diss }}$ is for that variable. For the analysis of changes with all variables covarying, we obtain one-dimensional linear fits for all dissipating cases. For the analysis of changes in a single variable from a reference case with all other variables held constant, we calculate the slope $\delta \psi / \delta t_{\text {diss }}$ also for all dissipating cases. We also compute trends for the two-dimensional space spanned by strongly correlated variables $z_{i}$ and $q_{t}^{\mathrm{BL}}$ as a two-dimensional linear fit of all the points to estimate the relationship between $t_{\text {diss }}$ and the two variables $\left(z_{i}, q_{t}^{\mathrm{BL}}\right)$ as

$$
\Delta t_{\text {diss }} \approx \frac{\delta t_{\text {diss }}}{\delta z_{i}} \Delta z_{i}+\frac{\delta t_{\text {diss }}}{\delta q_{t}^{\mathrm{BL}}} \Delta q_{t}^{\mathrm{BL}} .
$$

The results of the different methods are shown in Table 2. We acknowledge that for the single-variable changes the linear trend results depend on the reference case and only a single reference case is considered here. For the dissipation time trends when all variables covary, the different linear fits are also an approximation since the behavior is likely to be nonlinear based on the nonlinearities in the entrainment and radiation parameterizations. The estimated trends should be interpreted with caution, as they are marginal views of the behavior in the multidimensional space and other variables will naturally vary and contribute to the overall impact.

The most consistent trend is the $\delta \psi / \delta t_{\text {diss }}$ response to changes in $z_{i}$. A greater change of $z_{i}$ is needed to influence $t_{\text {diss }}$ when all variables covary $\left(163.9 \mathrm{~m} \mathrm{~h}^{-1}\right)$ compared to when only $z_{i}$ varies and other variables are held constant $\left(50.40 \mathrm{~m} \mathrm{~h}^{-1}\right)$. The $\delta \psi / \delta t_{\text {diss }}$ response is least sensitive for changes in inversion-base height with cloud thickness held constant $\left(\left.z_{i}\right|_{h}, 320.9 \mathrm{~m} \mathrm{~h}^{-1}\right)$ probably because the $z_{i}$ change is not reinforced by changes in initial $h$. For $h$, we find a similar effect of covariability, requiring greater changes $\left(319.6 \mathrm{~m} \mathrm{~h}^{-1}\right)$ compared to when only $\left.h\right|_{z_{i}}$ was varied $\left(78.74 \mathrm{~m} \mathrm{~h}^{-1}\right)$.

The impact of $q_{t}^{\mathrm{BL}}$ on $t_{\mathrm{diss}}$ is strong, but the different approaches yield contradictory trends, as discussed in section $3 b(1)$. While the single-variable changes yielded a positive $\delta \psi / \delta t_{\text {diss }}$ response $\left(0.359 \mathrm{~g} \mathrm{~kg}^{-1} \mathrm{~h}^{-1}\right)$, the fit for $q_{t}^{\mathrm{BL}}$ when all variables covary $\left(-2.826 \mathrm{~g} \mathrm{~kg}^{-1} \mathrm{~h}^{-1}\right)$ and the fit in the $2 \mathrm{D}\left(q_{t}^{\mathrm{BL}}, z_{i}\right)$ space $\left(-21.11 \mathrm{~g} \mathrm{~kg}^{-1} \mathrm{~h}^{-1}\right)$ are both negative. Meanwhile, the constant cloud thickness analysis varying $\left.z_{i}\right|_{h}$ yields a similar value to the trend with covariability $\left(-1.891 \mathrm{~g} \mathrm{~kg}^{-1} \mathrm{~h}^{-1}\right)$.

The comparison of the sensitivity of dissipation time when a single variable changes to sensitivity when all variables covary highlights the difficulty in finding universal cloud response trends because of the multidimensionality and intercorrelations in the dataset. Changing a single variable ignores its correlations with other variables and may create unrealistic meteorological conditions. Simplified covariability, such as variations of $\left.z_{i}\right|_{h}$ together with $q_{t}^{\mathrm{BL}}$ to minimize feedbacks related to strong changes of cloud thickness, can yield more realistic trends. However, we are not able to isolate the unique influence of one variable on dissipation time when all variables covary, and the net effects are composed of all the correlated variable contributions. However, the trends in cloud dissipation time when all variables covary can quantify the marginal impact of a variable in the most realistic way, in the sense that it is what we would observe in nature if we were to measure a limited number 
TABLE 2. Comparison of dissipation time trends for different variables; single-variable changes from a reference case, and when all variables covary. Only the most robust trends are included.

\begin{tabular}{|c|c|c|c|}
\hline $1 \mathrm{D}$ trend & Units & Single variations & Covariability trends $(95 \% \mathrm{CI})$ \\
\hline$\delta z_{i} / \delta t_{\text {diss }}$ & $\mathrm{m} \mathrm{h}^{-1}$ & 50.40 & $163.9(130.6,219.8)$ \\
\hline$\delta q_{t}^{\mathrm{BL}} / \delta t_{d i s s}$ & $\mathrm{~g} \mathrm{~kg}^{-1} \mathrm{~h}^{-1}$ & 0.359 & $-2.826(-5.465,-1.905)$ \\
\hline$\delta \Delta_{i} \theta_{l} / \delta t_{\text {diss }}$ & $\mathrm{Kh}^{-1}$ & 3.398 & $5.627(3.571,13.27)$ \\
\hline$\delta \mathrm{SHF} / \delta t_{\text {diss }}$ & $\mathrm{W} \mathrm{m} \mathrm{m}^{-2} \mathrm{~h}^{-1}$ & -26.35 & $-9.974(-48.24,-5.562)$ \\
\hline$\delta T_{\text {sky }} / \delta t_{\text {diss }}$ & $\mathrm{Kh}^{-1}$ & -8.556 & $-15.92(-42.75,-9.781)$ \\
\hline $1 \mathrm{D}$ trend & Units & Cloud thickness variations $\left(\left.h\right|_{z_{i}}\right)$ & Covariability trends $(95 \% \mathrm{CI})$ \\
\hline$\delta h / \delta t_{\text {diss }}$ & $\mathrm{m} \mathrm{h}^{-1}$ & 78.74 & $319.6(190.6,989.7)$ \\
\hline $2 \mathrm{D}$ trend & Units & Constant thickness variations $\left(\left.z_{i}\right|_{h}\right)$ & Covariability trends $(95 \% \mathrm{CI})$ \\
\hline$\delta z_{i} / \delta t_{\text {diss }}$ & $\mathrm{m} \mathrm{h}^{-1}$ & 320.9 & $171.1(130.1,249.7)$ \\
\hline$\delta q_{t}^{\mathrm{BL}} / \delta t_{\text {diss }}$ & $\mathrm{g} \mathrm{kg}^{-1} \mathrm{~h}^{-1}$ & -1.891 & $-21.11(7.486,-4.380)$ \\
\hline
\end{tabular}

of variables. Still, covariability effects are found to be too important to ignore, and thus, they should be considered in sensitivity analyses in order to improve prediction models.

The timing of dissipation may also affect the importance of some variables, as noted by Burleyson and Yuter (2015) in explaining why breakup rates of marine Sc are stronger in the late morning. Over coastal land, when $t_{\text {diss }}$ is closer to noon, wind speed and solar irradiance are greater than in the early morning and the same relative change in these variables would cause a larger absolute change in advective cooling and solar heating. This dependence on dissipation timing could apply to all variables with diurnal cycles, such as $\bar{u}$, Bo (as it is applied to surface fluxes over land), and $\mathrm{SW}_{i}$. In fact, Figs. 5j-o show that most cases resulting in early dissipation times are caused by a larger range of forcing variables than later dissipation times. Because of this spread in the early morning cases, the dissipation trends can be affected. Elucidating the extent of this impact is left for future work and it can indeed help to move forward to more realistic predictions.

While the physical processes described are consistent with the statistical results in this paper, simplifications may affect real dissipation trends: 1) The wind speed time series was simplified to allow a more standardized comparison. 2) Uncertainties exist in the estimation of $D$ and Bo. 3) The ABL is assumed to be well mixed. 4) Decoupling is not considered in the MLM, which might influence the real trends related to $z_{i}$ and dissipation time even though cases that were initially decoupled were removed from the analysis. Even though this means that the prediction skill of the model is currently not sufficient to predict real dissipation times (as discussed in appendix D), it also means that the complex results obtained are a pure consequence of the covariability within the dataset. If covariability has such a great influence on the results of a simple model such as the MLM, it will probably have it to a greater extent in more complex models and in nature.

\section{Conclusions}

We have studied the effects of several variables on the predicted dissipation time of Sc clouds over a coastal region using a realistic dataset and a two column mixedlayer model. The dataset included $195 \mathrm{Sc}$ days in the summers of 2014-17 in Southern California, with 15 variables acting as initial and forcing parameters in the MLM.

The main findings are summarized as follows:

- This work confirmed the importance of initial ABL height and cloud thickness in coastal Sc dissipation, in agreement with the trends of cloudiness for marine Sc. If these two variables could be measured more accurately and time-resolved in coastal areas using lidar, solar forecasts in the area could be improved.

- Covariability results, in which perturbations to one variable are accompanied by correlated variations in other variables related to initial conditions and forcings from a sample of 195 cloudy days, differ greatly from a traditional, single-variable sensitivity analysis. In most cases, covariability only strengthened or diminished the trend of a variable (albeit sometimes substantially), while in other cases the trend was the complete opposite.

- For example, lower ABL total water mixing ratio and larger Bowen ratio delay cloud dissipation with covariability while they accelerate dissipation time as single variables or in previous studies (Ghonima et al. 2016).

- Covariability also provides a different perspective on how sea-breeze advection can affect dissipation time compared to previous Sc studies over coastal land (Ghonima et al. 2016), affecting initially thinner clouds more than thicker ones. 
- Covariability effects are uniquely observable in our analysis and could not have been observed with a traditional sensitivity analysis. The use of a model instead of observed data ensures that the trends observed are solely a consequence of the covariability in the dataset and not of unknown or unobservable effects stemming from real-world complexities. Given the importance of covariability, modeling studies with sensitivity analyses should include covariability in the scenario generation.

- Dissipation times predicted by the MLM correlate only weakly to observed dissipation times, likely due to the simplicity of the model.

Future work should examine correlations in other coastal Sc regions in order to study the extent of regional influence on the variables. Another topic of interest is the influence of realistic wind conditions on coastal dissipation time.

Acknowledgments. We thank E. Wu, H. Yang, B. Akyurek, and X. Zhong for helpful discussion and comments for this work. We thank the reviewers for their comments that improved the manuscript. MZZ is funded by CONICYT PFCHA/Doctorado Becas Chile/2015-72160605. The authors declare no conflict of interest. We thank Minghua Ong for editorial assistance.

\section{APPENDIX A}

\section{Nomenclature}

\section{a. Roman symbols}

$A \quad$ In-cloud entrainment efficiency

$A_{\mathrm{CBL}} \quad$ Convective $\mathrm{ABL}$ entrainment efficiency

$A_{1}, A_{2}$ Constants for the shortwave radiative flux

$c_{1}, c_{2} \quad$ Constants for the longwave radiative flux

$C_{f} \quad$ Bulk transfer coefficient for surface fluxes

$C_{p} \quad$ Mean heat capacity of dry air in the ABL

$d^{2} \quad$ Squared distance for the STI method

$D \quad$ ABL large-scale horizontal divergence

$f_{w} \quad$ Filter for westerly wind

$F \quad$ Total net radiative flux

$F_{\text {LW }} \quad$ Net longwave radiation flux

$F_{\text {SW }} \quad$ Net shortwave radiation flux

$g \quad$ Gravitational acceleration

$h \quad$ Cloud thickness

$k \quad$ Constant for the shortwave radiative flux

$L_{l v} \quad$ Mean latent heat of vaporization in the ABL

$\mathrm{LW} \downarrow_{i} \quad$ Downwelling longwave flux at $z_{i}$

$n_{b}^{\mathrm{RH}} \quad$ Points below $z_{b}^{\mathrm{RH}}$ in the radiosonde

$p \quad$ Pressure $p_{00}$

$q$

$q_{l}$

$q_{\text {sat }}$

$q_{t}$

$q_{v}$

$R_{d}$

$R_{v}$

$\mathrm{Ri}$

$\mathbf{s}$

$\mathrm{SW}_{i}$

$t_{\text {diss }}$

$T_{b}$

$T_{\text {cld }}$

$T_{\mathrm{sc}}$

$T_{\text {sky }}$

$u$

$\mathbf{u}(t)$

$\frac{\bar{u}}{w^{\prime} \theta_{l}^{\prime}}$

$\frac{w^{\prime} \theta_{l}^{\prime}}{w^{\prime} \theta_{v}^{\prime}}$

$\overline{w^{\prime} q_{t}^{\prime}}$

$w_{*}$

$w_{e}$

$w_{\text {sub }}$

$z$

$z_{b}$

$z_{b}^{\mathrm{RH}}$

$\left.z_{i}\right|_{h}$

$z_{i}$

$z_{i}^{+}$

$z_{i t}$

b. Greek symbols

$\alpha \quad$ Constant for the longwave radiative flux

$\alpha_{w}(t) \quad$ Wind direction

$\beta \quad$ Constant for the shortwave radiative flux

$\gamma \quad$ Constant for the longwave radiative flux

$\delta \psi / \delta t_{\text {diss }} \quad$ Change in $\psi$ to delay $t_{\text {diss }}$ by $1 \mathrm{~h}$

$\Delta x$

$\Delta T$

$\theta$

$\theta_{l}$

$\theta_{v}$

$\mu_{0}$

$\xi$

$\Pi$

$\rho$

$\sigma$

$\tau_{\mathrm{SW}}(z)$

$\tau_{\mathrm{LW}}(z)$

Reference pressure $(1000 \mathrm{hPa})$

Constant for the shortwave radiative flux

Liquid water mixing ratio

Water saturation mixing ratio

Total water mixing ratio

Water vapor mixing ratio

Specific gas constant for dry air

Specific gas constant for water vapor

Bulk Richardson number

Auxiliary variable for the STI method

Shortwave irradiance above the cloud

Predicted dissipation time

Temperature at cloud base

Mean cloud temperature

Mean temperature below cloud

Effective sky temperature

Wind speed for large-scale advection

Wind velocity vector

Buoyancy flux

Vertical turbulent flux of $q_{t}$

Convective vertical velocity scale

Entrainment rate

Height

Cloud-base height

Radiosonde cloud-base height

Changes of $z_{i}$ maintaining constant $h$

Inversion-base height

Just above inversion-base height

Inversion-top height

Distance between ocean and land columns

Temperature inversion strength

Potential temperature

Liquid water potential temperature

Virtual potential temperature

Cosine of the solar zenith angle

Tuning parameter for the STI method

Exner function

Air density in the ABL

Stefan-Boltzmann constant

Cloud optical depth for shortwave radiation

(zero at cloud top)

Cloud optical depth for longwave radiation

(zero at cloud top) 
$\tau_{\mathrm{LW}, b} \quad$ Cloud optical depth at cloud base for longwave radiation

$\phi \quad$ Conversion efficiency for land surface fluxes

$\omega \quad$ Pressure vertical velocity

$\nabla_{h} \quad$ Horizontal gradient operator

\section{c. Abbreviations}

Bo Bowen ratio

GHI Global horizontal irradiance

LHF Latent heat flux at the ocean surface

LTS Lower-tropospheric stability

MLM Mixed-layer model

Sc Stratocumulus

SHF Sensible heat flux at the ocean surface

STI Steady thickness initialization

SZA Solar zenith angle

\section{d. Subscripts and superscripts}

$\psi^{\mathrm{BL}} \quad$ Well-mixed value of $\psi$ in the ABL

$\psi^{3 \mathrm{~km}} \quad$ Value of $\psi$ at $z=3 \mathrm{~km}$

$\psi_{0} \quad$ Value of $\psi$ at the surface

$\psi_{b} \quad$ Value of $\psi$ at the cloud base

$\psi_{\text {cld }} \quad$ Value of $\psi$ evaluated in the cloud region

$\psi_{i} \quad$ Value of $\psi$ at the inversion base

$(\psi)_{\text {new }} \quad$ New value of $\psi$ to maintain constant $h$

$(\psi)_{\text {old }}$ Original value of the variable $\psi$

$\Delta_{i} \psi \quad$ Inversion jump of $\psi$

\section{APPENDIX B}

\section{Mixed-Layer Model}

\section{a. Governing equations}

The state of the well-mixed ABL is described by inversion-base height $z_{i}$, total water mixing ratio $q_{t}=$ $q_{v}+q_{l}$, and liquid water potential temperature $\theta_{l} \approx \theta-$ $L_{l v} q l /\left(C_{p} \Pi\right)$, where $q_{v}$ is the water vapor mixing ratio, $q_{l}$ is the liquid water mixing ratio, $\Pi=\left(p / p_{00}\right)^{R_{d} / C_{p}}$ is the Exner function, $L_{l v}$ is the latent heat of vaporization, $C_{p}$ is the heat capacity of dry air, $p$ is pressure, $p_{00}=1000 \mathrm{hPa}$, and $R_{d}$ is the specific gas constant for dry air.

The governing equations of the MLM are the air mass, energy, and moisture balances [Eqs. (B1), (B3), and (B4)], which describe the average state of the ABL through the well-mixed variables $q_{t}^{\mathrm{BL}}$ and $\theta_{l}^{\mathrm{BL}}$. In the airmass balance [Eq. (B1)], entrainment, subsidence velocity, and large-scale advection determine the evolution of the ABL depth $z_{i}$ :

$$
\frac{\partial z_{i}}{\partial t}=w_{e}+w_{\text {sub }}-u \nabla_{h} z_{i}
$$

where $w_{e}$ is the entrainment rate, $w_{\text {sub }}$ is the subsidence rate, $u$ is horizontal wind speed, and $\nabla_{h}$ is the large-scale horizontal gradient operator. The subsidence rate at the top of the $\mathrm{ABL}, w_{\mathrm{sub}}$, is parameterized by constant horizontal divergence $D$ within the ABL:

$$
w_{\mathrm{sub}}=-D \times z_{i}
$$

In the heat balance [Eq. (B3)], turbulent fluxes, radiation, and large-scale advection drive the evolution of the temperature in the ABL:

$$
\frac{\partial \theta_{l}^{\mathrm{BL}}}{\partial t}=-\frac{\partial}{\partial z}\left(\overline{w^{\prime} \theta_{l}^{\prime}}(z)+\frac{F(z)}{\rho C_{p}}\right)-u \nabla_{h} \theta_{l}^{\mathrm{BL}},
$$

where $\overline{w^{\prime} \theta_{l}^{\prime}}(z)$ is the turbulent flux of liquid potential temperature and $F(z)$ is the vertical profile of radiative flux.

In the total water content balance [Eq. (B4)], we do not consider precipitation fluxes and subsequently, only turbulent fluxes and large-scale advection are present:

$$
\frac{\partial q_{t}^{\mathrm{BL}}}{\partial t}=-\frac{\partial}{\partial z} \overline{w^{\prime} q_{t}^{\prime}}(z)-u \nabla_{h} q_{t}^{\mathrm{BL}},
$$

where $\overline{w^{\prime} q_{t}^{\prime}}(z)$ is the turbulent flux of total water mixing ratio.

\section{b. Horizontal advection}

To describe ocean-land interaction, we model the evolution of two columns: one over the ocean and the other over land (Fig. 1). Due to the dominant wind direction from the ocean to the land, the ocean column model does not contain any advection terms, i.e., the last terms in [Eqs. (B1), (B3), and (B4)] are removed. For the land column, the advection terms depend on both ocean and land conditions:

$$
\begin{aligned}
& u \nabla_{h} \theta_{l}^{\mathrm{BL}}=\frac{u}{\Delta x}\left(\theta_{l, \text { land }}^{\mathrm{BL}}-\theta_{l, \text { ocean }}^{\mathrm{BL}}\right), \\
& u \nabla_{h} q_{t}^{\mathrm{BL}}=\frac{u}{\Delta x}\left(q_{t, \text { land }}^{\mathrm{BL}}-q_{t, \text { ocean }}^{\mathrm{BL}}\right),
\end{aligned}
$$

where $u$ is the wind speed and $\Delta x=30 \mathrm{~km}$ is the distance between the two columns. The associated coupling time scales $\Delta x / u$ range between 1.3 and $3.6 \mathrm{~h}$ at noon, when the wind speed is maximum, and between 3.1 and $8.4 \mathrm{~h}$ at night.

\section{c. Entrainment parameterization}

The entrainment rate is parameterized through buoyancy flux contributions (Ghonima et al. 2016, their section $4 \mathrm{~b}$ ). The total entrainment rate is the sum of contributions from surface and cloud regions, where each amount is proportional to a convective velocity 
scale, $w_{*}$, and inversely proportional to a bulk Richardson number, Ri:

$$
\begin{aligned}
w_{e} & =w_{e, 0}+w_{e, \mathrm{cld}}=A_{\mathrm{CBL}} \frac{w_{*_{0}}}{\mathrm{Ri}_{0}}+A \frac{w_{*_{\mathrm{cld}}}}{\mathrm{Ri}_{\mathrm{cld}}} \\
& =\left.1.25 \frac{A_{\mathrm{CBL}}}{\Delta_{i} \theta_{v}} \overline{w^{\prime} \theta_{v}^{\prime}}\right|_{0}+2.5 \frac{A}{h \Delta_{i} \theta_{v}} \int_{z_{b}}^{z_{i}} \overline{w^{\prime} \theta_{v}^{\prime}}(z) d z,
\end{aligned}
$$

where, at the surface, the constant $A_{\mathrm{CBL}}=0.2$ (Deardorff 1976) is a clear convective boundary layer (CBL) entrainment efficiency, $w_{* 0}$ is the surface convective velocity scale, and $\mathrm{Ri}_{0}$ is the surface bulk Richardson number. For the cloud region, $A$ is an entrainment efficiency coefficient (Grenier and Bretherton 2001) that includes evaporative enhancement effects, $w_{* \text { cld }}$ is a cloud convective velocity scale, and $\mathrm{Ri}_{\text {cld }}$ is the bulk Richardson number in the cloud region. Last, $\Delta_{i} \theta_{v}$ is the inversion jump of virtual potential temperature, and $\overline{w^{\prime} \theta_{v}^{\prime}}(z)$ is the buoyancy flux with $\left.\overline{w^{\prime} \theta_{v}^{\prime}}\right|_{0}$ as its surface value. The buoyancy flux uses a vertical profile of dry and moist coefficients that were updated at each iteration and were calculated differently for the subcloud and cloud regions, following Cuijpers and Duynkerke (1993, their appendix A).

Some cases resulted in negative entrainment when using this parameterization, and were discarded from the analysis. When analyzing the entrainment rate, algebraic manipulation yields an explicit equation:

$$
w_{e}=\frac{w_{e, 0}+\frac{2.5 A}{h \Delta_{i} \theta_{v}} \int_{z_{b}}^{z_{i}}\left\{C_{1}\left[\left(1-\frac{z}{z_{i}}\right)\left(\left.\overline{w^{\prime} \theta_{l}^{\prime}}\right|_{0}+\frac{F_{0}}{\rho C_{p}}\right)+\frac{z}{z_{i}} \frac{F_{i}}{\rho C_{p}}-\frac{F(z)}{\rho C_{p}}\right]+C_{2}\left[\left.\left(1-\frac{z}{z_{i}}\right) \overline{w^{\prime} q_{t}^{\prime}}\right|_{0}\right]\right\} d z}{1+\frac{2.5 A}{h \Delta_{i} \theta_{v}} \int_{z_{b}}^{z_{i}} \frac{z}{z_{i}}\left(C_{1} \Delta_{i} \theta_{l}+C_{2} \Delta_{i} q_{t}\right) d z},
$$

where $C_{1}$ and $C_{2}$ are the moist coefficients. The denominator can be negative depending on the value of the integral. Assuming $C_{1}$ and $C_{2}$ are constants (which is a reasonable assumption), the criterion for negative entrainment becomes

$$
\frac{h}{2 z_{i}}\left(C_{1} \Delta_{i} \theta_{l}+C_{2} \Delta_{i} q_{t}\right)<-\frac{\Delta_{i} \theta_{v}}{2.5 A},
$$

which depends on many parameters and cannot be analyzed in a simple way. If we explore the condition for r.h.s. $=0$, with referential moist coefficients $C_{1}=0.5$ and $C_{2}=970 \mathrm{~K}$ (Ghonima et al. 2016, their section 4b), we obtain: $\Delta_{i} \theta_{l}<C_{2} / C_{1}\left|\Delta_{i} q_{t}\right| \approx 1.94\left|\Delta_{i} q_{t}\right|$. The CTEI criterion also relates the inversion jumps [van der Dussen et al. 2014, their Eq. (1)] and can be rewritten as $\Delta_{i} \theta_{l}<0.77 L_{l v} / C_{p}\left|\Delta_{i} q_{t}\right| \approx$ $1.915\left|\Delta_{i} q_{t}\right|$. Both conditions are very similar, suggesting that the cases close to the critical CTEI criterion can yield negative entrainment rates when using this parameterization. Our physical interpretation is that for cases where negative subcloud fluxes should develop, the integrated buoyancy flux in the ABL cannot be described by the positive in-cloud buoyancy flux alone, resulting in an artificial negative entrainment velocity.

\section{d. Radiative model}

The net upward radiative flux includes longwave and shortwave contributions: $F=F_{\mathrm{LW}}-F_{\mathrm{Sw}}$ :

$$
\begin{aligned}
F_{\mathrm{SW}}(z)= & \frac{4}{3} \mathrm{SW}_{i}\left(q A_{1} e^{-k \tau_{\mathrm{SW}}(z)}-q A_{2} e^{k \tau_{\mathrm{SW}}(z)}\right. \\
& \left.-\beta e^{-\tau_{\mathrm{SW}}(z) / \mu_{0}}\right)+\mu_{0} \mathrm{SW}_{i} e^{-\tau \mathrm{sw}(z) / \mu_{0}},
\end{aligned}
$$

where SZA is the solar zenith angle, $\mu_{0}=\cos (\mathrm{SZA})$, $\tau_{\mathrm{SW}}(z)$ is the cloud optical depth (zero at cloud top) [Duynkerke et al. 2004, their Eqs. (6) and (7)] calculated with an effective radius of $10 \mu \mathrm{m}, A_{1}$ and $A_{2}$ come from boundary conditions of the radiative transfer equation, and $k, q$ and $\beta$ are constants that depend on $\mu_{0}$ and optical properties of cloud droplets (Duynkerke et al. 2004, their appendix).

The longwave contribution $F_{\mathrm{LW}}$ depends on three temperatures: $T_{\mathrm{sc}}$ taken as the mean temperature of the subcloud region; $T_{\text {cld }}$ taken as the mean temperature in the cloud region, and $T_{\text {sky }}$ taken as an effective radiative temperature of the sky:

$$
\begin{aligned}
F_{\mathrm{LW}}(z)= & \gamma \sigma\left[\left(T_{\mathrm{cld}}^{4}-T_{\mathrm{sky}}^{4}\right) c_{1} e^{-\alpha \tau_{\mathrm{LW}, b}}+\left(T_{\mathrm{sc}}^{4}-T_{\mathrm{cld}}^{4}\right) c_{2}\right] e^{\alpha \tau_{\mathrm{LW}}(z)} \\
& +\left[\left(T_{\mathrm{cld}}^{4}-T_{\mathrm{sky}}^{4}\right) c_{2} e^{\alpha \tau_{\mathrm{LW}, b}}+\left(T_{\mathrm{sc}}^{4}-T_{\mathrm{cld}}^{4}\right) c_{1}\right] e^{-\alpha \tau_{\mathrm{LW}}(z)},
\end{aligned}
$$

where $\sigma$ is the Stefan-Boltzmann constant, $\tau_{\mathrm{LW}}(z)$ is the cloud optical depth [Larson et al. 2007, their Eqs. (6) and (7)], and $\tau_{\mathrm{LW}, b}$ is the maximum optical depth (at cloud base). The parameters $\alpha, c_{1}, c_{2}$, and $\gamma$ are terms derived from the radiation transfer equation (Ghonima et al. 2016, their appendix B).

\section{e. Surface and cloud-top fluxes}

The surface fluxes of moisture $\left.\overline{w^{\prime} q_{t}^{\prime}}\right|_{0}$ and temperature $\left.\overline{w^{\prime} \theta_{l}^{\prime}}\right|_{0}$ depend on the type of the surface. For the ocean column, the SHF and LHF are fixed during the day. 
For the land column, the surface fluxes depend on the Bowen ratio Bo. A part of the net radiation flux at the surface $F_{0}$ is converted into a moisture and a heat flux released to the ABL [Eqs. (B12) and (B13)]:

$$
\begin{aligned}
& \left.\overline{w^{\prime} q_{t}^{\prime}}\right|_{0, \text { land }}=\phi \frac{1}{1+\mathrm{Bo}} \frac{F_{0}}{\rho C_{p}}, \\
& \left.\overline{w^{\prime} \theta_{l}^{\prime}}\right|_{0, \text { land }}=\phi \frac{\mathrm{Bo}}{1+\mathrm{Bo}} \frac{F_{0}}{\rho C_{p}},
\end{aligned}
$$

where $\phi=0.88$ is the efficiency at which net radiation is converted into surface fluxes (Ghonima et al. 2016).

At the top of the ABL, the turbulent fluxes of moisture $\left.\overline{w^{\prime} q_{t}^{\prime}}\right|_{i}$ and temperature $\left.\overline{w^{\prime} \theta_{l}^{\prime}}\right|_{i}$ depend on the entrainment rate $w_{e}$ and the sharp inversion jumps of moisture [Eq. (B14)] and temperature [Eq. (B15)], respectively (Lilly 1968):

$$
\begin{aligned}
& \left.\overline{w^{\prime} q_{t}^{\prime}}\right|_{i}=-w_{e} \Delta_{i} q_{t}, \\
& \left.\overline{w^{\prime} \theta_{l}^{\prime}}\right|_{i}=-w_{e} \Delta_{i} \theta_{l} .
\end{aligned}
$$

\section{APPENDIX C}

\section{Data}

\section{a. Variables}

The parameterizations and equations included in the MLM determine our variables of interest. We gather data from different sources for the years 2014-17, MaySeptember. In the following, variables are grouped by their data source.

\section{b. Radiosondes: $z_{i}, \theta_{l}(z), q_{t}(z)$}

We obtain 1200 UTC radiosonde data (reported at 0400 LST, launched at 0300 LST) from the NKX Miramar Marine Corps Air Station in Southern California $\left(32.85^{\circ} \mathrm{N}\right.$, $\left.117.2^{\circ} \mathrm{W}\right)$. The station is located $10 \mathrm{~km}$ away from the coast, where the shoreline is aligned meridionally.

Radiosonde profiles are postprocessed into well-mixed layers to make them compatible with the MLM. First, temperature inversions in the lowest $3 \mathrm{~km}$ are detected. The largest temperature inversion is assumed to cap the mixed layer if it is sufficiently strong $(\Delta T>3 \mathrm{~K})$, yielding inversion-base and -top heights, $z_{i}$ and $z_{i t}$ respectively. Clouds are assumed to exist where RH exceeds 95\% below $z_{i}$, with the radiosonde cloud base $z_{b}^{\mathrm{RH}}$ defined as the lowest point that meets that condition. Decoupled days cannot be represented in an MLM, and thus, we discard these days using the criterion $\left|\theta_{v b}-\theta_{v 0}\right|>1 \mathrm{~K}$ (Ghate et al. 2015), where $\theta_{v b}$ and $\theta_{v 0}$ are the virtual potential temperature at the radiosonde cloud base and at the surface, respectively.

The well-mixed $q_{t}[$ [Eq. (C1)] is an ABL average of the radiosonde measurements. Since $q_{l}$ is not measured by radiosondes, $q_{t}$ will be underestimated, but in view of the limited resolution of the data and that $q_{t} \gg q_{l}$, this approach is reasonable. Above the inversion, we consider $q_{t}$ to be constant, and also compute it as an average up to $3 \mathrm{~km}$ :

$$
q_{t}(z)= \begin{cases}q_{t}^{\mathrm{BL}}=\frac{1}{z_{i}} \int_{0}^{z_{i}} q_{v}(z) d z & \text { if } \quad z<z_{i} \\ q_{t}^{3 \mathrm{~km}}=\frac{1}{3 \mathrm{~km}-z_{i t}} \int_{z_{i t}}^{3 \mathrm{~km}} q_{v}(z) d z & \text { if } \quad z \geq z_{i} .\end{cases}
$$

For $\theta_{l}(z)$, we follow a similar averaging approach [Eq. (C2)]. If there are more than 5 data points below $z_{b}^{\mathrm{RH}}$, the average is computed in the subcloud region to avoid phase-change heating effects on $\theta(z)$; otherwise, all points in the ABL are averaged (including all the points is not a major concern for $q_{t}$ since $\left.q_{t} \gg q_{l}\right)$. Above the ABL, we obtain a linear fit for $\theta\left(z_{i t}<z<3 \mathrm{~km}\right)$ :

$$
\theta_{l}(z)=\left\{\begin{array}{lll}
\theta_{l}^{\mathrm{BL}}=\frac{1}{z_{i}} \int_{0}^{z_{i}} \theta(z) d z & \text { if } \quad z<z_{i} \text { and } n_{b}^{\mathrm{RH}} \leq 5 \\
\theta_{l}^{\mathrm{BL}}=\frac{1}{z_{b}^{\mathrm{RH}}} \int_{0}^{\mathrm{z}_{b}} \theta(z) d z & \text { if } \quad z<z_{i} \text { and } n_{b}^{\mathrm{RH}}>5 \\
a z+b & \text { if } \quad z \geq z_{i} \quad \text { with } a, b \text { from linear fit for } \theta\left(z_{i t}<z<3 \mathrm{~km}\right),
\end{array}\right.
$$

where $n_{b}^{\mathrm{RH}}$ is the number of points below $z_{b}^{\mathrm{RH}}$.

We assume that the inversion occurs over an infinitesimally thin layer, defining the inversion jumps of total water mixing ratio and liquid water potential temperature:

$$
\begin{aligned}
& \Delta_{i} q_{t}=q_{t}^{3 \mathrm{~km}}-q_{t}^{\mathrm{BL}}, \\
& \Delta_{i} \theta_{l}=\theta_{l}\left(z=z_{i}^{+}\right)-\theta_{l}^{\mathrm{BL}},
\end{aligned}
$$

where $z_{i}^{+}$is just above the inversion height. 

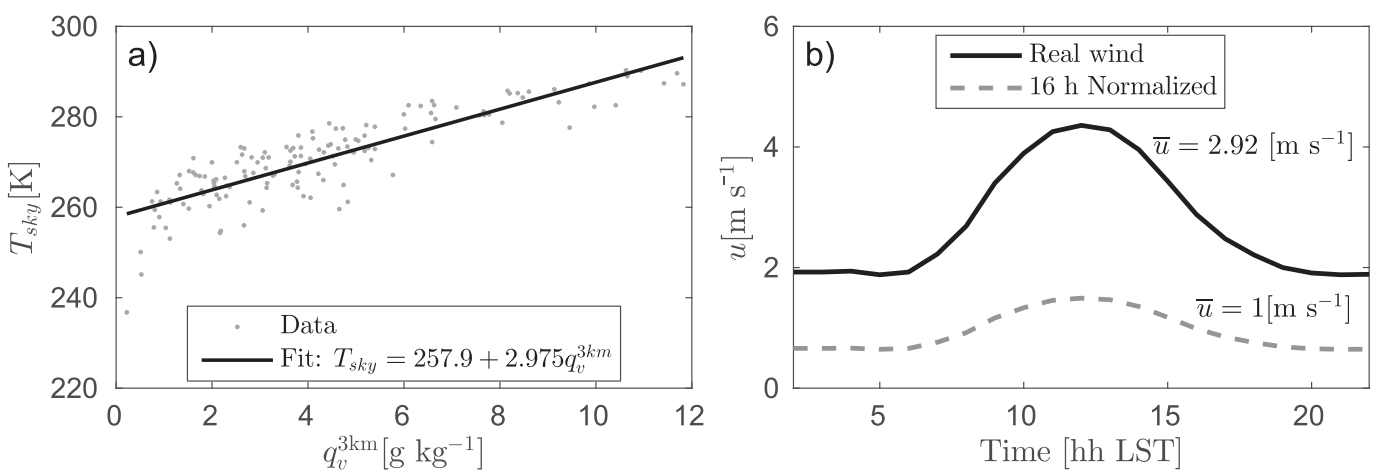

FIG. C1. (a) Sky effective radiative temperatures for the dataset of 209 cloudy days as a function of water content above the cloud and below $3 \mathrm{~km}$. The sky effective radiative temperatures were obtained with Streamer (Key and Schweiger 1998). (b) Climatological daily wind profile for the NKX station (10-yr average), showing the original wind speed profile and the wind speed normalized by its 16-h average.

\section{c. Radiative and clear-sky models: $T_{\text {sky }}$ and $\mathrm{SW}_{i}$}

We obtain the effective sky temperature $T_{\text {sky }}$ for the longwave radiative model using the Streamer radiative transfer model (Key and Schweiger 1998). Inputs are the temperature and relative humidity soundings, which are extended to $100 \mathrm{~km}$ with a U.S. Standard Atmosphere, 1976. We compute $T_{\text {sky }}$ as the blackbody temperature from the longwave downwelling flux at the top of the cloud as LW $\downarrow_{i}=\sigma T_{\text {sky }}^{4}$. Figure C1a shows that skies with more water content experience a smaller net radiative cooling at the cloud top.

For the shortwave radiation model, $\mathrm{SW}_{i}$ is the solar irradiance incident on the top of the Sc cloud. We estimate $\mathrm{SW}_{i}$ as the GHI from a clear-sky model (Ineichen and Perez 2002). Monthly climatological Linke turbidities for that location are input to the clear-sky model.

\section{d. NWP models: Bo, D}

We estimate the Bowen ratio Bo at NKX by analyzing in-house operational runs of the WRF Model using the Noah land surface model (Skamarock et al. 2008). Bo is the ratio between SHF and LHF at the surface at the nearest grid point to the NKX station. Hourly output is averaged between 0800 and 1500 LST to yield a (constant) daily Bo that is input to the MLM simulations. Land surface models in WRF are known to differ from measurements (Wharton et al. 2016); land surface models tend to produce $\mathrm{Bo} \approx 1$ with small temporal deviations.

We estimate large-scale divergence $D$ from the NAM Forecasting System as the partial derivative of pressure vertical velocity $\omega$ with respect to pressure in the ABL. The differences are computed between 975 and $850 \mathrm{hPa}$ [Eq. (C5)]. We average $D$ spatially over an area of 21 grid points over the ocean around $\left(38.15^{\circ} \mathrm{N}, 117.5^{\circ} \mathrm{W}\right)$ and then temporally with a 3-day moving average:

$$
D=-\frac{\partial \omega}{\partial p} \approx-\frac{\omega(975 \mathrm{hPa})-\omega(850 \mathrm{hPa})}{975 \mathrm{hPa}-850 \mathrm{hPa}} .
$$

\section{e. METAR and NDBC: $\bar{u}$, SLP, SHF, LHF}

For coastal regions in Southern California, the sea breeze acts during the day with a strong westerly component, usually beginning around 0800 LST and peaking around 1200 LST. A $16 \mathrm{~h}$ average (between 0500 and 2100 LST) wind speed $\bar{u}$ is computed from the METAR weather station at NKX. All westerly winds (with direction between $180^{\circ}$ and $360^{\circ}$ ) are scalar averaged:

$$
\bar{u}=\frac{1}{16 \mathrm{~h}} \int_{t=0500 \mathrm{LST}}^{t=2100 \mathrm{LST}} f_{w}[\mathbf{u}(t)] d t,
$$

where $\mathbf{u}(t)$ is the wind velocity with magnitude $u(t)$ and direction $\alpha_{w}(t)$ and $f_{w}[\mathbf{u}(t)]$ is the filter for considering westerly directions only:

$$
f_{w}(\mathbf{u})= \begin{cases}u(t) & \text { if } \quad \alpha_{w}(t) \in\left(180^{\circ}, 360^{\circ}\right) \\ 0 & \text { else }\end{cases}
$$

A 10-yr average daily wind profile is shown in Fig. C1b. The daily profile is normalized by its $16-\mathrm{h}$ average wind speed and then rescaled with the daily $\bar{u}$.

We estimate SLP as the daily average SLP at the METAR weather station at NKX.

Surface turbulent fluxes in the ocean column, which are fixed in the MLM, are computed from wind and sea surface temperature data. Daily averages of SST are obtained at the Torrey Pines Outer station from the NDBC (NOAA 2017). Surface fluxes are computed using a bulk transfer coefficient $C_{f}=1.2 \times 10^{-3}$ (Blossey et al. 2013), the average SST and wind speed, and assuming that the temperature and moisture above 
the surface is the same as that of the initial state of the ABL:

$$
\begin{aligned}
& \mathrm{SHF}=\rho C_{p} \bar{u} C_{f}\left(\mathrm{SST}-\theta_{l}^{\mathrm{BL}}\right), \\
& \mathrm{LHF}=\rho L_{\mathrm{lv}} \bar{u} C_{f}\left[q_{\mathrm{sat}}(\mathrm{SST})-q_{t}^{\mathrm{BL}}\right],
\end{aligned}
$$

where $q_{\text {sat }}$ is the saturation mixing ratio.

\section{APPENDIX D}

\section{Dissipation Time Comparison}

We estimate dissipation time over NKX $t_{\text {diss }}^{\text {SAT }}$ using a satellite derived low cloudiness product (Clemesha et al. 2016; Wu et al. 2018). This dataset has a 4-km spatial resolution and 30-min time resolution. We obtain $t_{\mathrm{diss}}^{\mathrm{SAT}}$ at the closest pixel to NKX as the time when skies are clear for at least $1 \mathrm{~h}$ afterward. We neglect $t_{\text {diss }}^{\mathrm{SAT}}$ before 0500 LST since they are unlikely to be caused by Sc, which would thicken during the night.

We also estimate dissipation time $t_{\text {diss }}^{\mathrm{GH}}$ from 1-s global horizontal irradiance data measurements at the UC San Diego campus, $5 \mathrm{~km}$ west of NKX (Zamora Zapata et al. 2019). Only Sc to clear transitions are included; a Sc cloud is assumed to exist if the early sounding is well mixed and has a cloud presence ( $\mathrm{RH}>95 \%)$, while also checking sky imagery at the time of the breakup to discard other cloud types or the presence of upper-level clouds. A $t_{\text {diss }}^{\mathrm{GHI}}$ event is recorded when the clear-sky index is close to 1 for the following $5 \mathrm{~min}$.

There is a strong correlation between $t_{\text {diss }}^{\mathrm{SAT}}$ and $t_{\text {diss }}^{\mathrm{GHI}}$ $\left(0.79, R^{2}=0.6\right)$, while the correlation between MLM modeled dissipation time and $t_{\mathrm{diss}}^{\mathrm{SAT}}$ and $t_{\text {diss }}^{\mathrm{GHI}}$ is 0.26 and 0.28 with $R^{2}$ of 0.06 and 0.07 , respectively.

Ideally the MLM dissipation times would be more correlated to the observed dissipation times. But given the MLM assumptions, parameter uncertainties, adjustment of initial conditions, and neglect of some physical processes, the relatively small correlation is not surprising. We maintain that the MLM based analysis of parameter correlations is valuable and superior to the alternatives. Strengths of the MLM application in this analysis include the following: (i) The MLM represents most of the physical processes. (ii) The MLM has been validated by Ghonima et al. (2016) against LES, demonstrating that the MLM is capable of correctly predicting the evolution of an idealized coastal Sc cloud. (iii) Initial conditions are approximated through elaborate sourcing from best available models and measurement sources. (iv) The simple geometric domain of the MLM prevents real-world complexities such as varying topography and $3 \mathrm{D}$ effects from affecting the results. (v) Simulation days are limited to conditions that are represented in the model, e.g., days with decoupling are removed. However, as evidenced by the need for adjustment of initial conditions, there are inconsistencies in the initial conditions and/or shortcomings in the model. As a result, the MLM results live in a virtual/model world. But we maintain that to analyze variability and covariability between variables an internally consistent albeit somewhat idealistic modeling approach is preferable over sparse measurements and 3D models such as WRF that also perform poorly and introduce additional complexities. This paper is the first to attempt a comprehensive evaluation of variability and covariability of atmospheric parameters for Sc dissipation over land. It is our hope that in the future models are improved and models can be better coupled to measurements to narrow the gap between model results and observations.

\section{APPENDIX E}

\section{Linear Approximation to $q_{t}^{\mathrm{BL}}\left(\boldsymbol{z}_{i}, \boldsymbol{\theta}_{l}^{\mathrm{BL}}\right)$}

For a cloud to form given ABL height $z_{i}$ and wellmixed liquid water potential temperature $\theta_{l}^{\mathrm{BL}}$, the total water content at ABL top must surpass saturation by a small amount, which is condensed into a cloud: $q_{t}^{\mathrm{BL}}=q_{\mathrm{sat}}\left(z_{i}, \theta_{l}^{\mathrm{BL}}\right)+q_{l}\left(z_{i}\right)$. Since $q_{l}\left(z_{i}\right) \ll q_{t}^{\mathrm{BL}}$, we investigate the behavior of $q_{\text {sat }}\left(z, \theta_{l}\right)$ :

$$
q_{\mathrm{sat}}=\frac{\varepsilon}{p(z) / e_{s}\left(z, \theta_{l}\right)-1}
$$

where $\varepsilon=0.622$ and pressure follows the hydrostatic assumption $p(z) \approx p_{0}-\rho g z$. The water saturation pressure $e_{s}$ is given by the August-Roche-Magnus approximation:

$$
e_{s}=\kappa_{1} \exp \left(\frac{\kappa_{2} T_{c}}{\kappa_{3}+T_{c}}\right),
$$

where $\kappa_{1}=610.94 \mathrm{~Pa}, \kappa_{2}=17.625, \kappa_{3}=243.04$, and $T_{c}$ is temperature in degrees Celsius. To estimate temperature near the cloud top, we will assume that we are just surpassing saturation with an infinitesimally thin cloud and use the dry adiabatic lapse rate:

$$
T_{c}=T_{0}-\Gamma_{d} z-273.15 \mathrm{~K},
$$

where $\Gamma_{d}=g / C_{p}$ is the dry adiabatic lapse rate and $T_{0}$ is surface temperature, which is related to the well-mixed $\theta_{l}$ and surface pressure $p_{0}$ :

$$
T_{0}=\theta_{l}\left(\frac{p_{0}}{p_{00}}\right)^{R_{d} / C_{p}} .
$$



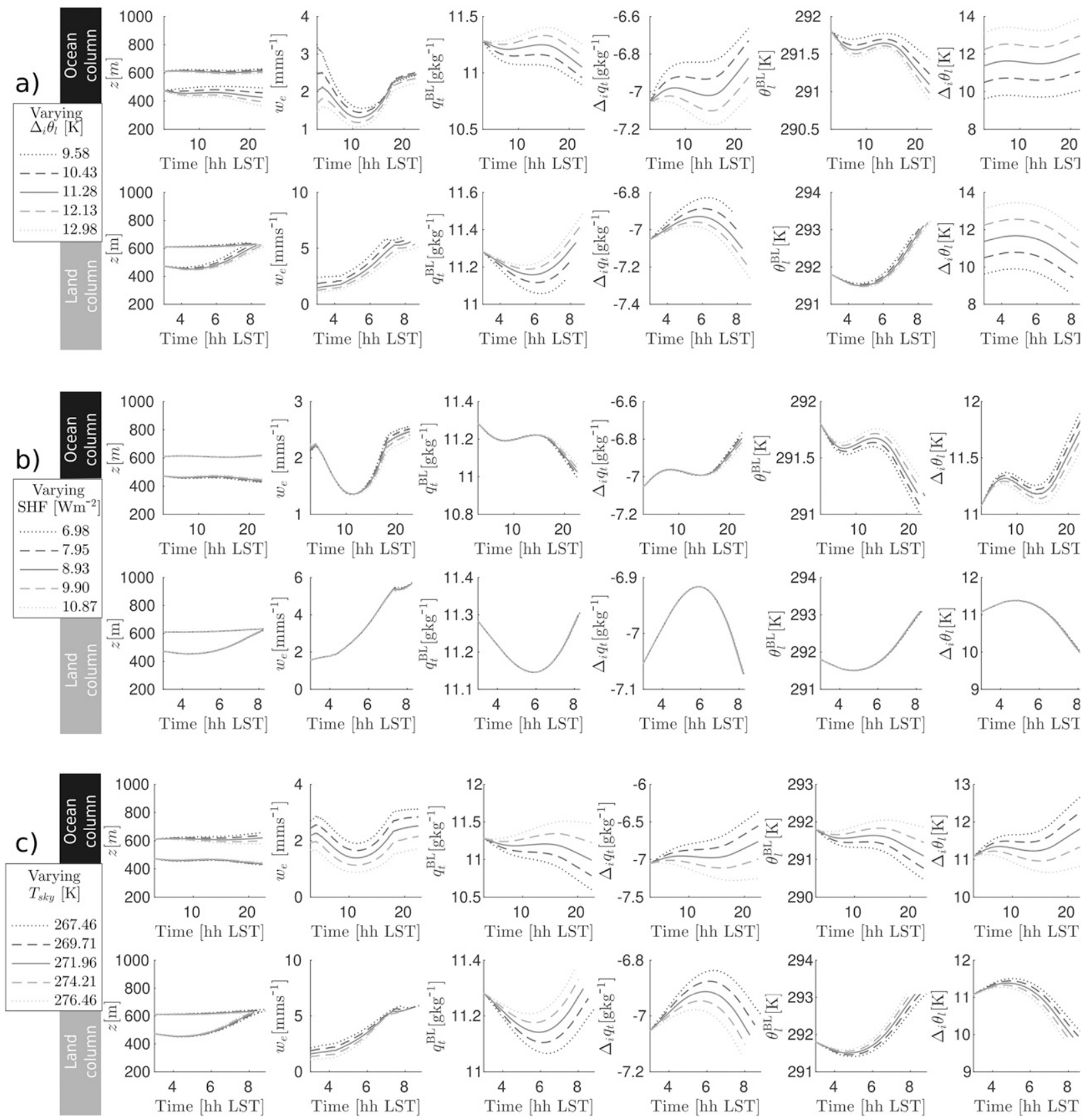

FIG. F1. Cloud evolution properties for the ocean column (top row for each panel) and (bottom row for each panel) land columns for single-variable changes of (a) $\Delta_{i} \theta_{l}$, (b) SHF, and (c) $T_{\text {sky }}$ over the idealized reference case. (left to right) Cloud boundaries, entrainment rate, $q_{t}^{\mathrm{BL}}, \Delta_{i} q_{t}, \theta_{l}^{\mathrm{BL}}$, and $\Delta_{i} \theta_{l}$.

With these assumptions, we can estimate $\partial q_{\mathrm{sat}} / \partial z$ and $\partial q_{\mathrm{sat}} / \partial \theta_{l}$ and evaluate them at the observed means of $z_{i}$, $\theta_{l}$, and $p_{0}$ (Table 1), obtaining

$$
\frac{\partial q_{\mathrm{sat}}}{\partial \theta_{l}}=\frac{\varepsilon p}{\left(\frac{p}{e_{s}}-1\right)^{2}} \frac{p \kappa_{2} \kappa_{3}}{e_{s}\left(\kappa_{3}+T_{c}\right)^{2}} \approx 0.6964 \mathrm{~g} \mathrm{~kg}^{-1} \mathrm{~K}^{-1},
$$

$$
\frac{\partial q_{\mathrm{sat}}}{\partial z}=\frac{-\varepsilon}{\left(\frac{p}{e_{s}}-1\right)^{2}} \frac{\frac{p \kappa_{2} \Gamma_{d} \kappa_{3} e_{s}}{\left(\kappa_{3}+T_{c}\right)^{2}}-\rho g e_{s}}{e_{s}^{2}} \approx-0.0055 \mathrm{~g} \mathrm{~kg}^{-1} \mathrm{~m}^{-1},
$$

which yields results similar to the linear fit coefficients in Fig. 7a. This indicates that even with the assumptions 
made here, the linear relationship between $z_{i}, \theta_{l}^{\mathrm{BL}}$, and $q_{t}^{\mathrm{BL}}$ closely follows the saturation condition.

\section{APPENDIX F}

\section{Detailed Cloud Evolution for Single-Variable Changes}

We present the time evolution of the ocean and land columns for the single-variable changes of three parameters in Fig. F1. For stronger $\Delta_{i} \theta_{l}$, the resulting colder $\theta_{l}^{\mathrm{BL}}$ indicates that the effect of weaker entrainment dominates over the warmer entrained air. For SHF, the changes over the ocean column barely affect the land column. Last, a lower $T_{\text {sky }}$ results in a cooler $\mathrm{ABL}$, indicating that the radiative cooling dominates over the increased entrainment of warmer air.

\section{REFERENCES}

Akyurek, B. O., and J. Kleissl, 2017: Closed-form analytic solution of cloud dissipation for a mixed-layer model. J. Atmos. Sci., 74, 2525-2556, https://doi.org/10.1175/JAS-D-16-0303.1.

Blossey, P. N., and Coauthors, 2013: Marine low cloud sensitivity to an idealized climate change: The CGILS LES intercomparison. J. Adv. Model. Earth Syst., 5, 234-258, https://doi.org/ 10.1002/jame.20025.

Bony, S., and J.-L. Dufresne, 2005: Marine boundary layer clouds at the heart of tropical cloud feedback uncertainties in climate models. Geophys. Res. Lett., 32, L20806, https://doi.org/ 10.1029/2005GL023851.

Bretherton, C. S., and M. C. Wyant, 1997: Moisture transport, lower-tropospheric stability, and decoupling of cloud-topped boundary layers. J. Atmos. Sci., 54, 148-167, https://doi.org/ 10.1175/1520-0469(1997)054<0148:MTLTSA > 2.0.CO;2.

Burleyson, C. D., and S. E. Yuter, 2015: Patterns of diurnal marine stratocumulus cloud fraction variability. J. Appl. Meteor. Climatol., 54, 847-866, https://doi.org/10.1175/JAMCD-14-0178.1.

Chlond, A., and A. Wolkau, 2000: Large-eddy simulation of a nocturnal stratocumulus-topped marine atmospheric boundary layer: An uncertainty analysis. Bound.-Layer Meteor., 95, 31-55, https://doi.org/10.1023/A:1002438701638.

Christensen, M. W., G. G. Carrió, G. L. Stephens, and W. R. Cotton, 2013: Radiative impacts of free-tropospheric clouds on the properties of marine stratocumulus. J. Atmos. Sci., 70, 3102-3118, https://doi.org/10.1175/JAS-D-12-0287.1.

Clemesha, R. E. S., A. Gershunov, S. F. Iacobellis, A. P. Williams, and D. R. Cayan, 2016: The northward march of summer low cloudiness along the California coast. Geophys. Res. Lett., $\mathbf{4 3}$, 1287-1295, https://doi.org/10.1002/2015GL067081.

Cuijpers, J. W. M., and P. G. Duynkerke, 1993: Large eddy simulation of trade wind cumulus clouds. J. Atmos. Sci., $\mathbf{5 0}$, 3894-3908, https://doi.org/10.1175/1520-0469(1993)050<3894: LESOTW $>2.0 . \mathrm{CO} ; 2$.

Dal Gesso, S., A. P. Siebesma, S. R. de Roode, and J. M. van Wessem, 2014: A mixed-layer model perspective on stratocumulus steady states in a perturbed climate. Quart. J. Roy. Meteor. Soc., 140, 2119-2131, https://doi.org/10.1002/qj.2282.
Deardorff, J. W., 1976: On the entrainment rate of a stratocumulustopped mixed layer. Quart. J. Roy. Meteor. Soc., 102, 563-582, https://doi.org/10.1002/qj.49710243306.

_- 1980: Cloud top entrainment instability. J. Atmos. Sci., 37, 131-147, https://doi.org/10.1175/1520-0469(1980)037<0131: CTEI>2.0.CO;2.

Duynkerke, P. G., and J. Teixeira, 2001: Comparison of the ECMWF reanalysis with FIRE I observations: Diurnal variation of marine stratocumulus. J. Climate, 14, 1466-1478, https://doi.org/ 10.1175/1520-0442(2001)014<1466:COTERW>2.0.CO;2.

— tions of the diurnal cycle of the EUROCS stratocumulus case. Quart. J. Roy. Meteor. Soc., 130, 3269-3296, https://doi.org/ 10.1256/qj.03.139.

Fang, M., B. A. Albrecht, V. P. Ghate, and P. Kollias, 2014: Turbulence in continental stratocumulus, part I: External forcings and turbulence structures. Bound.-Layer Meteor., 150, 341-360, https://doi.org/10.1007/s10546-013-9873-3.

Ghate, V. P., M. A. Miller, B. A. Albrecht, and C. W. Fairall, 2015: Thermodynamic and radiative structure of stratocumulustopped boundary layers. J. Atmos. Sci., 72, 430-451, https:// doi.org/10.1175/JAS-D-13-0313.1.

Ghonima, M. S., J. R. Norris, T. Heus, and J. Kleissl, 2015: Reconciling and validating the cloud thickness and liquid water path tendencies proposed by R. Wood and J. J. van der Dussen et al. J. Atmos. Sci., 72, 2033-2040, https://doi.org/ 10.1175/JAS-D-14-0287.1.

,$- \ldots$, and J. Kleissl, 2016: Factors controlling stratocumulus cloud lifetime over coastal land. J. Atmos. Sci., 73, 2961-2983, https://doi.org/10.1175/JAS-D-15-0228.1.

Grenier, H., and C. S. Bretherton, 2001: A moist PBL parameterization for large-scale models and its application to subtropical cloud-topped marine boundary layers. Mon. Wea. Rev., 129, 357-377, https://doi.org/10.1175/1520-0493(2001)129<0357: AMPPFL $>2.0 . \mathrm{CO} ; 2$.

Halliwell, G. R., and J. S. Allen, 1987: The large-scale coastal wind field along the west coast of North America, 1981-1982. J. Geophys. Res., 92, 1861-1884, https://doi.org/10.1029/ JC092iC02p01861.

Hanson, H. P., 1991: Marine stratocumulus climatologies. Int. J. Climatol., 11, 147-164, https://doi.org/10.1002/joc.3370110204.

Hartmann, D. L., M. E. Ockert-Bell, and M. L. Michelsen, 1992: The effect of cloud type on Earth's energy balance: Global analysis. J. Climate, 5, 1281-1304, https://doi.org/10.1175/15200442(1992)005<1281:TEOCTO > 2.0.CO;2.

Ineichen, P., and R. Perez, 2002: A new airmass independent formulation for the Linke turbidity coefficient. Sol. Energy, $\mathbf{7 3}$, 151-157, https://doi.org/10.1016/S0038-092X(02)00045-2.

Jamaly, M., J. L. Bosch, and J. Kleissl, 2013: Aggregate ramp rates of distributed photovoltaic systems in San Diego county. IEEE Trans. Sustain. Energy, 4, 519-526, https://doi.org/ 10.1109/TSTE.2012.2201966.

Key, J. R., and A. J. Schweiger, 1998: Tools for atmospheric radiative transfer: Streamer and FluxNet. Comput. Geosci., 24, 443-451, https://doi.org/10.1016/S0098-3004(97)00130-1.

Klein, S. A., and D. L. Hartmann, 1993: The seasonal cycle of low stratocumulus clouds. J. Climate, 6, 1587-1606, https://doi.org/ 10.1175/1520-0442(1993)006<1587:TSCOLS > 2.0.CO;2.

__ _ _ _ and J. R. Norris, 1995: On the relationships among low-cloud structure, sea surface temperature, and atmospheric circulation in the summertime northeast Pacific. J. Climate, $\mathbf{8}$, 1140-1155, https://doi.org/10.1175/1520-0442(1995)008<1140: OTRALC $>2.0 . \mathrm{CO} ; 2$. 
Kopec, M. K., S. P. Malinowski, and Z. P. Piotrowski, 2016: Effects of wind shear and radiative cooling on the stratocumulustopped boundary layer. Quart. J. Roy. Meteor. Soc., 142, 32223233, https://doi.org/10.1002/qj.2903.

Kuo, H.-C., and W. H. Schubert, 1988: Stability of cloud-topped boundary layers. Quart. J. Roy. Meteor. Soc., 114, 887-916, https://doi.org/10.1002/qj.49711448204.

Larson, V. E., K. E. Kotenberg, and N. B. Wood, 2007: An analytic longwave radiation formula for liquid layer clouds. Mon. Wea Rev., 135, 689-699, https://doi.org/10.1175/MWR3315.1.

Lilly, D. K., 1968: Models of cloud-topped mixed layers under a strong inversion. Quart. J. Roy. Meteor. Soc., 94, 292-309, https://doi.org/10.1002/qj.49709440106.

Ma, Y.-F., J. G. Pedersen, W. W. Grabowski, M. K. Kopec, and S. P. Malinowski, 2018: Influences of subsidence and freetropospheric conditions on the nocturnal growth of nonclassical marine stratocumulus. J. Adv. Model. Earth Syst., 10, 2706-2730, https://doi.org/10.1029/2018MS001295.

McMichael, L. A., D. B. Mechem, S. Wang, Q. Wang, Y. L. Kogan, and J. Teixeira, 2019: Assessing the mechanisms governing the daytime evolution of marine stratocumulus using large-eddy simulation. Quart. J. Roy. Meteor. Soc., 145, 845-866, https:// doi.org/10.1002/qj.3469.

Mellado, J. P., 2017: Cloud-top entrainment in stratocumulus clouds. Annu. Rev. Fluid Mech., 49, 145-169, https://doi.org/ 10.1146/annurev-fluid-010816-060231.

Myers, T. A., and J. R. Norris, 2013: Observational evidence that enhanced subsidence reduces subtropical marine boundary layer cloudiness. J. Climate, 26, 7507-7524, https://doi.org/ 10.1175/JCLI-D-12-00736.1.

Nieuwstadt, F. T. M., and P. G. Duynkerke, 1996: Turbulence in the atmospheric boundary layer. Atmos. Res., 40, 111-142, https://doi.org/10.1016/0169-8095(95)00034-8.

NOAA, 2017: Recent observations from buoy $46225(32.933 \mathrm{~N}$ 117.391W)-Torrey Pines Outer, CA (100). NDBC, accessed DD MMM YYYY, http://www.ndbc.noaa.gov/station page.php? station $=46225$.

Noda, A. T., K. Nakamura, T. Iwasaki, and M. Satoh, 2014: Responses of subtropical marine stratocumulus cloud to perturbed lower atmospheres. SOLA, 10, 34-38, https://doi.org/ 10.2151/SOLA.2014-008.

Seethala, C., J. R. Norris, and T. A. Myers, 2015: How has subtropical stratocumulus and associated meteorology changed since the 1980s? J. Climate, 28, 8396-8410, https://doi.org/ 10.1175/JCLI-D-15-0120.1.

Skamarock, W. C., and Coauthors, 2008: A description of the Advanced Research WRF version 3. NCAR Tech. Note NCAR/TN-475+STR, 113 pp., https://doi.org/10.5065/ D68S4MVH.
Stevens, B., 2005: Atmospheric moist convection. Annu. Rev. Earth Planet. Sci., 33, 605-643, https://doi.org/10.1146/ annurev.earth.33.092203.122658.

van der Dussen, J. J., S. R. de Roode, and A. P. Siebesma, 2014: Factors controlling rapid stratocumulus cloud thinning. J. Atmos. Sci., 71, 655-664, https://doi.org/10.1175/JAS-D13-0114.1.

,-- , S. Dal Gesso, and A. P. Siebesma, 2015: An LES model study of the influence of the free tropospheric thermodynamic conditions on the stratocumulus response to a climate perturbation. J. Adv. Model. Earth Syst., 7, 670-691, https:// doi.org/10.1002/2014MS000380.

,$- \ldots$, and A. P. Siebesma, 2016: How large-scale subsidence affects stratocumulus transitions. Atmos. Chem. Phys., 16, 691-701, https://doi.org/10.5194/acp-16-691-2016.

Wellby, S. J., and N. A. Engerer, 2016: Categorizing the meteorological origins of critical ramp events in collective photovoltaic array output. J. Appl. Meteor. Climatol., 55, 1323-1344, https:// doi.org/10.1175/JAMC-D-15-0107.1.

Wharton, S., M. Simpson, J. Osuna, J. Newman, and S. Biraud, 2016: The role of surface energy exchange for simulating wind inflow: An evaluation of multiple land surface models in WRF for the Southern Great Plains site field campaign report. ARM Tech. Rep. DOE/SC-ARM-14-040, 28 pp., https://doi.org/10.2172/1254173.

Wood, R., 2012: Stratocumulus clouds. Mon. Wea. Rev., 140, $2373-$ 2423, https://doi.org/10.1175/MWR-D-11-00121.1.

—- and C. S. Bretherton, 2006: On the relationship between stratiform low cloud cover and lower-tropospheric stability. J. Climate, 19, 6425-6432, https://doi.org/10.1175/ JCLI3988.1.

Wu, E., R. E. S. Clemesha, and J. Kleissl, 2018: Coastal stratocumulus cloud edge forecasts. Sol. Energy, 164, 355-369, https:// doi.org/10.1016/j.solener.2018.02.072.

$\mathrm{Xu}, \mathrm{X}$., and H. Xue, 2015: Impacts of free-tropospheric temperature and humidity on nocturnal nonprecipitating marine stratocumulus. J. Atmos. Sci., 72, 2853-2864, https://doi.org/ 10.1175/JAS-D-14-0387.1

Zamora Zapata, M., E. Wu, and J. Kleissl, 2019: Irradiance enhancement events in the coastal stratocumulus dissipation process. Solar World Congress, Santiago, Chile, International Solar Energy Society, https://doi.org/10.6084/m9.figshare.10304846.v1.

Zelinka, M. D., D. A. Randall, M. J. Webb, and S. A. Klein, 2017: Clearing clouds of uncertainty. Nat. Climate Change, 7, 674678, https://doi.org/10.1038/nclimate3402.

Zhu, P., and Coauthors, 2005: Intercomparison and interpretation of single-column model simulations of a nocturnal stratocumulustopped marine boundary layer. Mon. Wea. Rev., 133, 2741-2758, https://doi.org/10.1175/MWR2997.1. 